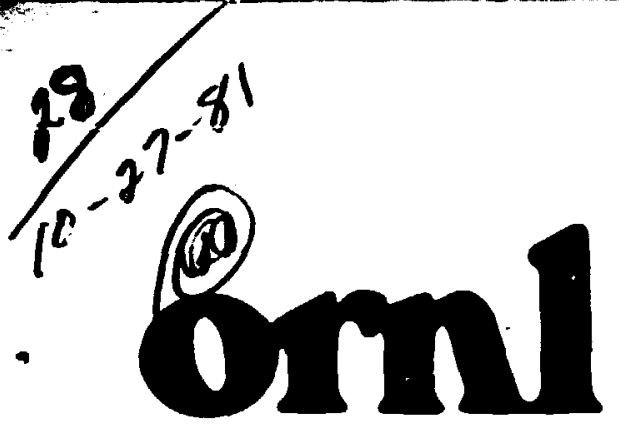

$\bullet$

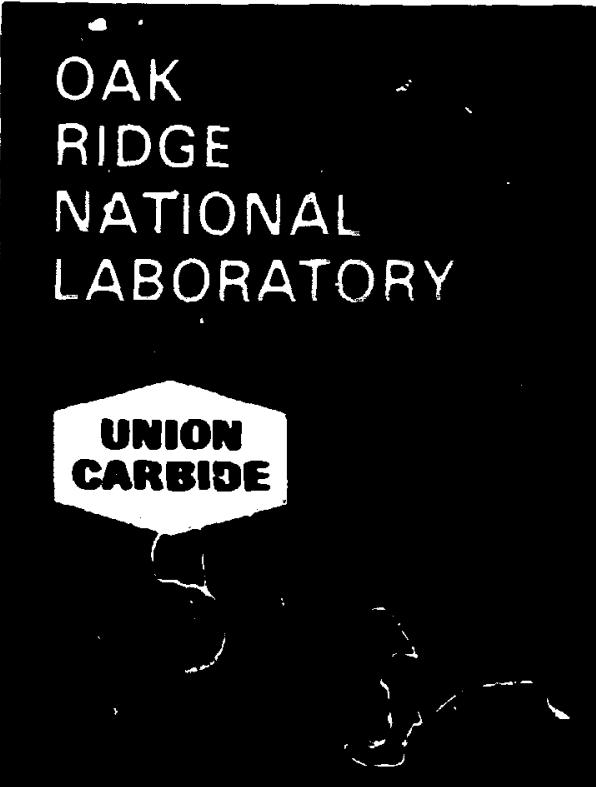

(2)

B7954

Design of a Reactor System for the Synthesis of Titanium Diboride

M. E. Tsui

H. A. Epstein

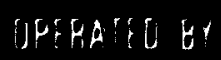

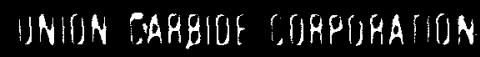

¿IS THF UNIFO :IATE:,

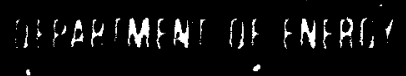




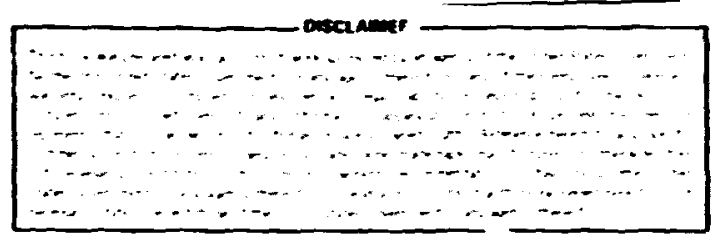

ORNL/MIT-333

Contract No. N-7405-eng-26

\section{CHEMISTRY DIVIS:ON}

DESIGN OF A REACTOR SYSTEM FOR THE SYHTHESIS CF TITAMIU DIBORIDE

M.E. Tsui

H.A. Epste in

Consultants:

J. Brynestad. C.E. Bamberger, and R.L. Heestand

Date Published - October 1981

Oak Ridge Station School of Chemical Engineering Practice Massachusetts Institute of Technology

C.H. Byers, Director

Oak Ridge National Laboratory

Oak Ridge, Tennessee 37830

operated by

Union Carbide Corporation

for the

Department of Energy 
1. Sumary $\ldots \ldots \ldots \ldots \ldots \ldots \ldots \ldots \ldots \ldots \ldots \ldots \ldots \ldots \ldots \ldots \ldots \ldots \ldots$

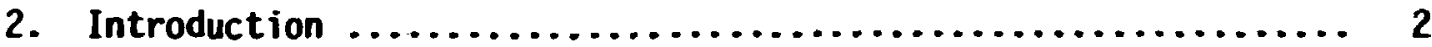

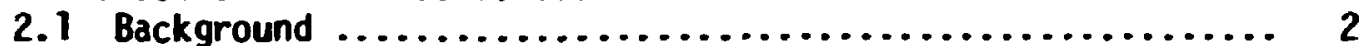

2.2 Objectives $\ldots \ldots \ldots \ldots \ldots \ldots \ldots \ldots \ldots \ldots \ldots \ldots \ldots \ldots \ldots \ldots$

3. Design Criteria .................................... 3

3.1 Operating Variables ............................... 3

3.2 Preparation Methods ............................ 5

3.3 Choice of Structural Materials ..................... 6

4. Design Resu'ts and Discussicn $\ldots \ldots \ldots \ldots \ldots \ldots \ldots \ldots \ldots \ldots \ldots \ldots$

4.1 Overall Design .................................... 6

4.2 Reaction System ............................... 8

4.2.1 Preheater .............................. 8

4.2.2 Reaction Chamber ........................ 12

4.3 Reactant Feed System ............................ 14

4.4 Collection System .............................. 14

4.5 Exhaust-Gas Disposal System .................... 17

4.6 Utility Requirements ........................... 17

4.7 Cost Estimation .............................. 18

5. Operating Details of the System $\ldots \ldots \ldots \ldots \ldots \ldots \ldots \ldots \ldots \ldots . \ldots \ldots$

5.1 Procedure .................................... 20

5.2 Safety Considerations $\ldots \ldots \ldots \ldots \ldots \ldots \ldots \ldots \ldots \ldots \ldots \ldots \ldots \ldots$

6. Proposed Experimental Plan ......................... 22

6.1 Optimal Conditions for Powder Formation ............. 22

6.1.1 Temperature ........................... 22

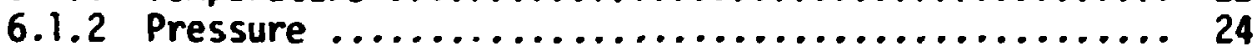

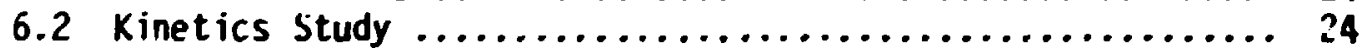

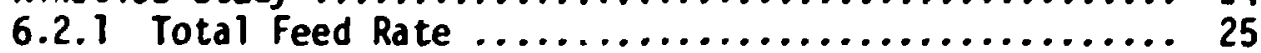

6.2.2 Feed Composition ........................ 25

6.2.3 Mass Balance Calculation .................. 25

7. Product Analysis $\ldots \ldots \ldots \ldots \ldots \ldots \ldots \ldots \ldots \ldots \ldots \ldots \ldots \ldots . \ldots \ldots$

8. Conclusions $\ldots \ldots \ldots \ldots \ldots \ldots \ldots \ldots \ldots \ldots \ldots \ldots \ldots \ldots \ldots \ldots \ldots \ldots$

9. Recommendations $\ldots \ldots \ldots \ldots \ldots \ldots \ldots \ldots \ldots \ldots \ldots \ldots \ldots \ldots \ldots$

10. Acknowlergments $\ldots \ldots \ldots \ldots \ldots \ldots \ldots \ldots \ldots \ldots \ldots \ldots \ldots \ldots \ldots$

11. Appendix .................................. 29

11.1 Thermodynamic Properties of Components .............. 29

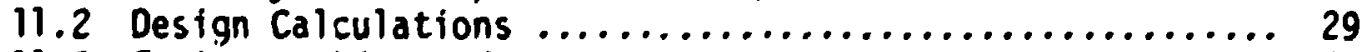

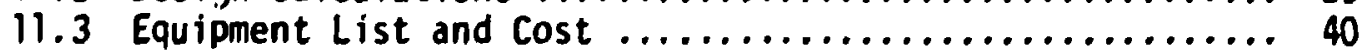

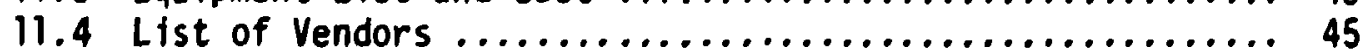

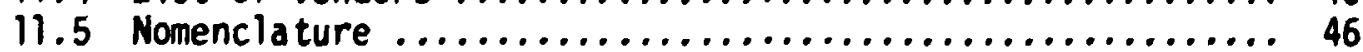

11.6 Literature References ......................... 48 


\section{SUWARY}

Titanium diboride is a hard, $r$ actory material with potential wide industrial uses, including electrode coatings and machine-tool surfaces. For exauple, $\mathrm{TiB}_{2}$ is being investigated as an inert carbon cathode coating for Hall cells, which are used in the production of aluninu. However, titanium diboride's utility is compromised by impurities such as oxides present in most commercial $\mathrm{TiB}_{2}$ powder, which cause the coating to disintegrate at grain boundaries. Thus, a method to prepare high-purity $\mathrm{TiB}_{2}$ is actively sought.

A laboratory-scale reactor system has been designed and is presented lere to produce pure $\mathrm{TiB}_{2}$ pouder by chemical vapor decomposition according to the following reaction:

$$
\mathrm{TiCl}_{4}(\mathrm{~g})+2 \mathrm{BCl}_{3}(\mathrm{~g})+5 \mathrm{H}_{2}(\mathrm{~g})=\mathrm{TiB}_{2}(\mathrm{~s})+10 \mathrm{HCl}(\mathrm{g})
$$

The system was designed to produce $4 \mathrm{~g} / \mathrm{h}$ of $\mathrm{TiB} 2$ and to retain maximum versatility of the operating variables over a wide variety of operating possibilities. An earlier thermodynamic study on the resction (1) suggested that the reaction is favored at high temperature and reduced pressure, with excess hydrogen in the feed.

Based on the Besmann study (1), the reactor was designed to be an alumina tube $3-3 / 8$ in. in ID $\times 30^{-}$in. long, capable of operating at a maximum temperature of $1700 \mathrm{~K}$ and at pressures ranging from 1 torr to atmospheric. The feed is preheated in the entry tube by on electrical resistance wire. A novel feature of this design is that $\mathrm{Cl}_{2}$ gas in the feed provides a flame in the reactor, supplying the heat of reaction directly to the reactants. The region within the $\mathrm{H}_{2}-\mathrm{Cl}_{2}$ flame will be at a sibstantially higher temperature than the surrounding gas or the reactor walls. Thus, it is anticipated that homogeneous nucleation will be favored.

Detailed sketches and equipment selection were completed in preparation for construction of the apparatus. The cost of the system, including feed and product collect: on systems, plus the reactor, was estimated to be about $\$ 24,500$ at current (1981) prices.

Finaliy, an experimental plan tu evaluate the performance of the system is presented, along with a suggested analytical procedure for the powder product and suggested system startup and shutdown procedures. 


\section{INTROOUCTIOH}

\subsection{Background}

Titanium diboride ( $T \mathrm{~B}_{2}$ ), a very hard, refractory material (melting point, $2800^{\circ} \mathrm{C}$ ), has wide industrial application. Its resistance to corrosion and chemical attack and its hardness make it an excellent protective coating, for example, as a carbon-cathode coating in the Hall process of aluminum electrolysis (7). Possessing high thermal and electrical conductivities, the diboride coating reduces appreciably the electrical demand of the process, which governs the economics of the Hall process. However, the use of $\mathrm{TiB}_{2}$ is limited by corrosion at the grain boundaries, which causes disintegration of the electrode. Oxide impurities present in all commercial $\mathrm{TiB}_{2}$ powders may cause this corrosion. Other commercial applications include cutting-tool surfaces and the coating of parts which see erosive service, such as in coal-1 iquefactioil plants. Currently it is commercially produced by a carbotheraic reduction method in which the oxides of titanium and boron are reduced by carbon to give $\mathrm{TiB}_{2}$ at high temperature by the following reaction:

$$
\mathrm{TiO}_{2}(\mathrm{~s})+\mathrm{B}_{2} \mathrm{O}_{3}(\mathrm{~s})+5 \mathrm{C}(\mathrm{s})=\mathrm{TiB}_{2}(\mathrm{~s})+5 \mathrm{CO}(\mathrm{g})
$$

This method leaves solid impurities such as titanium carbide, boron carbide, and unreacted oxides in the produrt.

Alternatively, it can be prepared by the thermochemical reduction cf titanium tetrachloride and boron trichloride by hydrogen at elevated temperatures. Subsequent deposition of the product on a heated substrate by heterogeneous nuclestion (l) occurs by the following overall reaction:

$$
\mathrm{TiCl}_{4}(g)+2 \mathrm{BCl}_{3}(\mathrm{~g})+5 \mathrm{H}_{2}(\mathrm{~g})=\mathrm{TiB}_{2}(\mathrm{~s})+10 \mathrm{HCl}(\mathrm{g})
$$

This method, known as chemical vapor deposition (CVD), is believed to produce a product of higher purity because only the solid diboride condenses from the gas. When powders are desired, the sol id layer must be ground from the substrate to a powder. However, the extreme hardness of $\mathrm{T}^{\mathrm{i}} \mathrm{B}_{2}$ causes impurities to be introduced during the grinding step. This could be avoided if reaction (2) can be effected in the gas phase by nomogeneous nucieation, thus forming TiB 2 powder directly. This methoc', which has been used successfully for producing $\mathrm{UO}_{2}$ powder by themical vapor decomposition (4), shculd produce high-purity $\mathrm{TiB}_{2}$. Since this approach has not been attempted, and since it shows substantial promise of being applicable, a design is required before a system can be built. 


\subsection{Objectives}

The ubjective of this study was to design a reactor system to synthesize $\mathrm{TiB}_{2}$ powder directly in the gas phase by homogeneous nucleation. Specific objectives included:

1. Design the reactor system, including all parts that are to be fabricated.

2. Compile a list of tems to purchase, proposed vendors, and current prices.

3. Estimate the construction cost, including materials, fabrication, and assenbly.

4. Determine operating limits for all the system variables and propose an experimental plan to test the system.

5. Investigate analytical metrods for product examination.

\section{DESIGN CRITERIA}

The reactor system was designed to produce $4 \mathrm{~g}$ of $\mathrm{TiB}_{2}$ per hour. Since the powder is to be produced by homogeneous nucleation in the gas phase, reaction methods must be found to enhance such homogeous nucleation and minimize heterogeneous nucleation on a substrate, such as the reactor walls. In addition, the system must be sufficier.tly flexible to permit controlled variation of the independent variables over wide operating ranges. These constraints directed investigation to the areas described below.

\subsection{Operating Variables}

The operating variables include temperature, pressure, reactant feed rates, and feed compositions. Operating ranges for these variables were calculated from the given production rate and thermodynamic data. Figure 1 shows the results of a thermodynamic study performed by Besmann and Spear (1). In Fig. la, the equilibrium conversion to $\mathrm{TiB}_{2}$, defined as the mole percentage of $\mathrm{TiCl}_{4}$ in the feed converted to $\mathrm{TiB}_{2}$, is plotted as a function of temperature at various pressures. Feed compositions are given in terms of the boron-to-titanium $[B /(B+T i)]$ and the chlorine-to-hydrsgen $[\mathrm{Cl} /(\mathrm{Cl}+\mathrm{H})]$ molar ratios. Pelcentage conversion increases with increasing temperature (ccnstant pressure) and decreases with increasing pressure (constant temperature). Thus, equilibrium production of $\mathrm{TiB}_{2}$ is favored by high temperature and low pressures. In Fig. Ib, the equifibrium conversion is plotted as a function of temperature at a fixed pressure and constant $\mathrm{B} /(\mathrm{B}+\mathrm{Ti})$ ratio for three values of $\mathrm{Cl} /(\mathrm{Cl}+\mathrm{H})$ ratio. Percentage conversion increases with increasing temperature [constant $\mathrm{Cl} /(\mathrm{Cl}+\mathrm{H})$ ] 


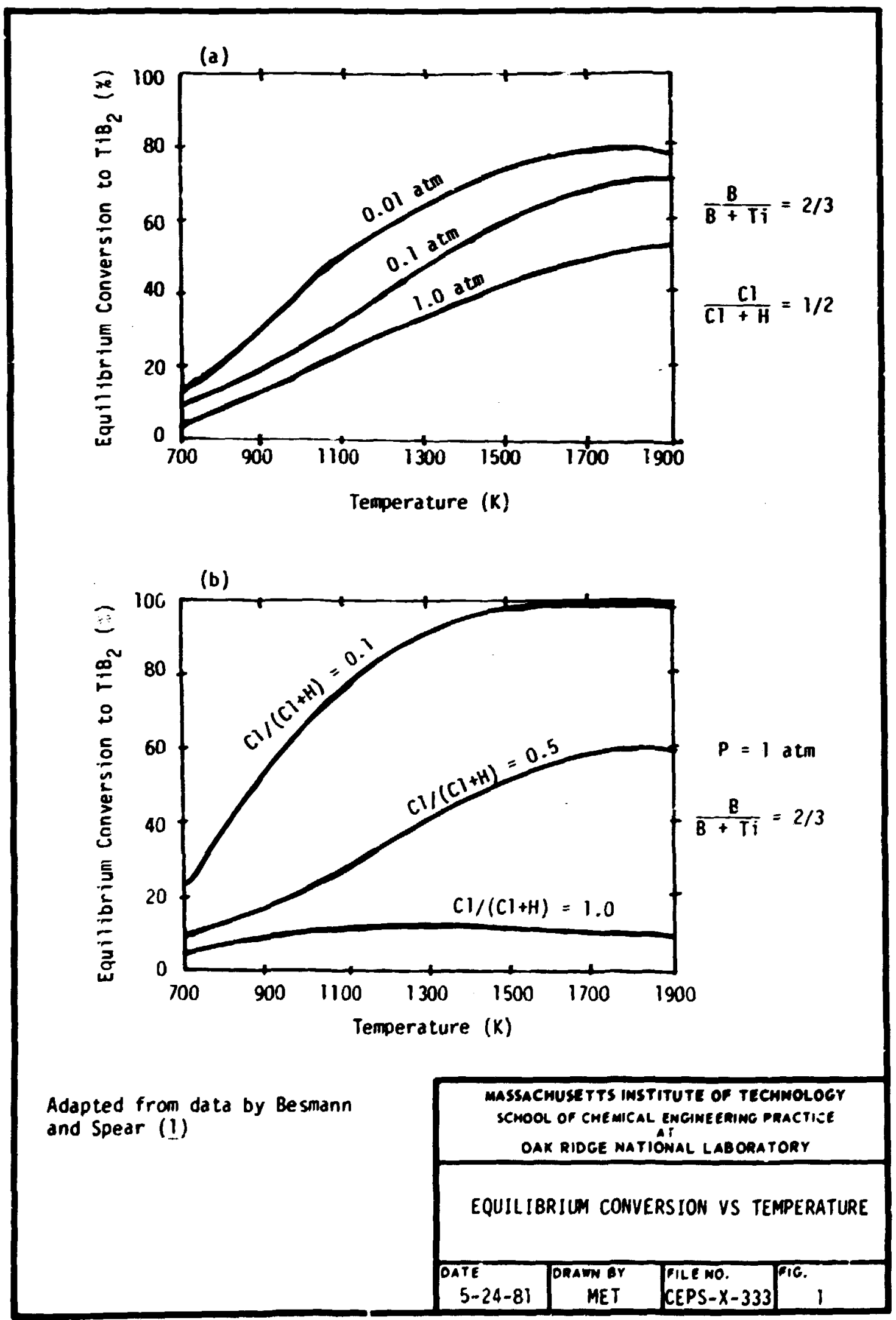


but decreases with increasing $\mathrm{Cl}(\mathrm{Cl}+\mathrm{H})$ ratio (constant temperature). Thus, equilibrium is favored at low $\mathrm{Cl} /(\mathrm{Cl}+\mathrm{H})$ ratios, indicating that excess hydrogen should be added to the feed.

Besmann also showed that tie $B /(B+T i)$ ratio in the feed affects the composition of the solid ootained. Any $\mathrm{BCl}_{3}$ in excess of stoichiometric amount $[B /(B+T i)>2 / 3]$ results in formation of elemental boron, which contaminates the product. Alternatively, any $\mathrm{TiCl}_{4}$ in excess of the stoichiometric amount $[\mathrm{B} /(\mathrm{B}+\mathrm{Ti})<2 / 3]$ results in formation of $\mathrm{TiCl}_{3}$.

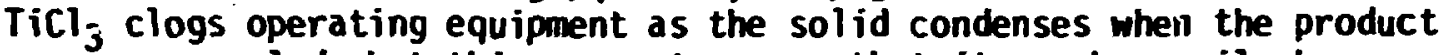
gases are cooled, but this property means that it can be easily be removed from $\mathrm{TiB}_{2}$ product by vaporization. Of the two products it is ouviously preferrable to form small amounts of $\mathrm{TiCl}_{3}$, which will vaporize during subsequent powder processing. Therefore, the indication of a slight excess of $\mathrm{TiCl}_{4}$ is probably prudent.

Using Besmann's thermodynamic considerations and considering the constraints imposed by construction material properties (Sect. 3.3), the following operating conditions were established as a design basis:

Temperature: $1700 \mathrm{~K}$ (maximum operatins temperature)

Pressure: $\quad 0.3 \mathrm{~atm}$

$\mathrm{Cl} /(\mathrm{Cl}+\mathrm{H}): 1 / 4$ (three times molar excess hydrogen)

$B /\{B+T i): 2 / 3$ (stoichiometric ratio)

The system was designed so that the operating conditions could be adjusted over a wide range. For example, the operating temperature can be varied from room temperature to a maximum of $1700 \mathrm{~K}$, and the pressure from 1 torr to atmospheric.

\subsection{Preparation Methods}

Flame processes have been used to produce refractory powders competitively with conventional methods $v$ : ing heated reactors $(5,6,12)$. The latter favors heterogeneous nucleation on the heated reactor wal1, which is hotter than the reactant gases. In flame processes, however, the reactant gases are directly heated by a flame produced from combustible feed gases. The reactor wall serves as insulation against heat loss and can be held at a lower temperature. Thus, homogeneous nucleation in the flame is kinetica ily favored. A unique feature of this design study is this flame-reactor concept, which uses a $\mathrm{H}_{2}-\mathrm{Cl}_{2}$ flame to provide the necessary heat of reaction to produce $\mathrm{TiB}_{2}$. 


\subsection{Choice of Structural Materials}

Alumina was chosen as the structural material for the praheaterreactor system. Alumina resists high temperatures (up to $2100 \mathrm{~K}$ ) and the corrosive gases used in the reaction. In addition, it is inexpensive and readily available. Stainless steel, which is corrosion resistant to the reaction materials at low temperatures, is specified for all piping and valves in the low-temperature portions of the equipment.

\section{DESIGN RESULTS AND DISCUSSION}

\subsection{Overal1 Design}

The reactor system is designed to produce $\mathrm{TiB}_{2}$ powder at the rate of $4 \mathrm{~g} / \mathrm{h}$ from gaseous $\mathrm{TiCl}_{4}, \mathrm{BCl}_{3}$, and $\mathrm{H}_{2}$. As shown in $\mathrm{Fig} .2$, the production system consists of four subsystems, including the reactor feed, product collection, and disposal systems. In the following sections, the design and operation of these subsystems is described in detail, along with cost and utility estimates. The remainder of the section is an overall description of the system.

In the feed system, $\mathrm{TiCl}_{4}$, which is a liquid at room temperature, is vaporized and mixed with the gaseous $\mathrm{Cl}_{2}$ and $\mathrm{BCl}_{3}$ before it enters the preheater tube. Hydrogen gas flows through the annulus outside the preheater tube. The flow of each gas is monitored by a mass flow meter. All gases are heated to reaction temperature by an electrical resistance wire wrapped around the preheater tube. The gases meet at the preheater exit. Hydrogen, forming the exterior of the reaction flame, diffuses into the reaction mixture. This provides a protective blanket between the reactor wall and the reactant mixture. This suppresses heterogeneous nucleation and promotes homogeneous nucleation by preventing the reacting gases from contacting the reactor wall. The $\mathrm{TiB}_{2}$ powder leaves the reaction chamber with the unreacted feed gases and $\mathrm{HCl}$, while any $\mathrm{TiCl}_{3}$ that is formed condenses as a solid on the cooled surfaces at the outlet end of the reactor. The product stream, at about $200^{\circ} \mathrm{C}$, then enters the collection traps, where the solid $\mathrm{TiB}_{2}$ is separated from the gases. Two interchangeable traps allow continuous operation while the powder is sampled or remo:zd.

The remaining gases, mostly unreacted $\mathrm{H}_{2}, \mathrm{HCl}$, and unreacted feed, pass through a mass flow meter, a vacuum pump (used to maintain the system pressure), and a packed-column scrubber. A gas-sample port is available in the line before the vacuum pump. The gas from the scrubber, which is mainly hydrogen, is mixed with methane and air and sent to a burner. The burner-product gases are vented. 


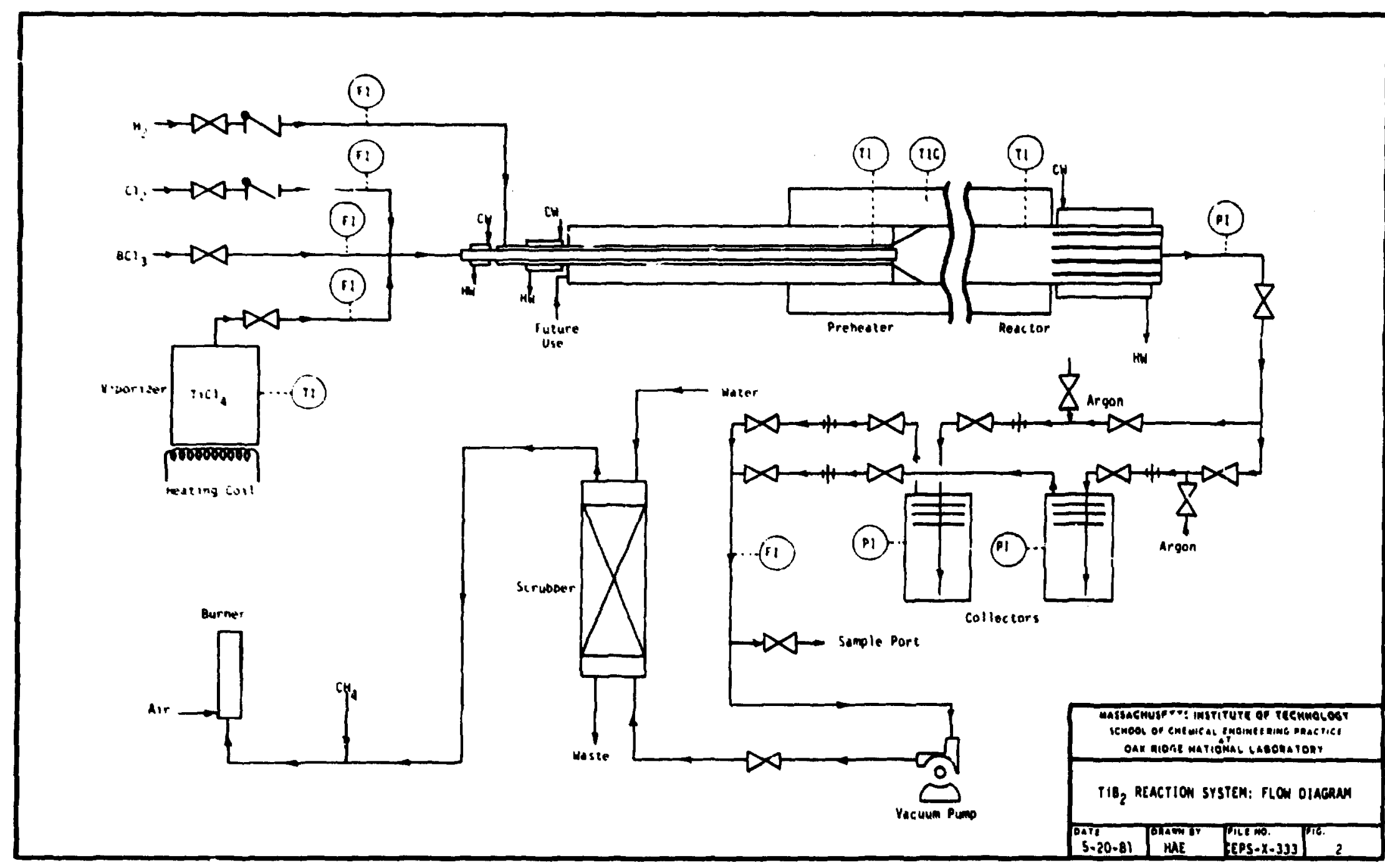




\subsection{Reaction System}

The reaction system consists of a preheater, a reaction chamber, and a cooling section, which are shown in detail in Figs. 3 and 4 . The system is contained in an alumina tube, 3-3/8 in. in 10 (3-3/4 in. OD) by 55 in. long, the reactor portion of which is encased in an insulated furnace which provides a constant wall temperature. The portion of the tube containing the preheater is coolea by natural convection, while a water jacket cuols the portion after the reaction chamber.

The material of choice for all tubes and internal parts of the reactorpreheater system is alumina, which can withstand the high temperature ( $1700 \mathrm{~K})$ and corrosive attack by all the materials used or produced in this process. The tubing and fittings in the cooler sections at the ends of the reactor are of stainless steel, while Viton rubber is used for the vacuum seals at each end of the reactor.

\subsubsection{Preheater}

The preheater, located inside a cylindrical housing, 3-3/8 in. in ID, consists of two concentric tubes, the inner having a $7 / 16$ in. ID and a 25-mil wall thickness, the outer having a 1 in.- ID and a 25-mil wall thickress (see Figs. 4 and 5). Alumina tuive of this size are not commercially available; hence, they must be !urchased as stock with the correct inside diameter and ground to the proper wall thickness. Hydrogen flows through the tube annulus, and the other three gases flow through the inner tube. The two tubes are sized such that the two streams have equal linear velocities to reduce eddies and turbulence at the point where the two streams meet (calculations are in Appendix 11.2.2). When the two streams enter the reactor, the hydrogen envelopes the chlorides, providing a gasenus blanket to prevent reaction on the wall of the reactor.

The preheater must supply $500 \mathrm{~W}$ of power to heat the gases to $1700 \mathrm{~K}$ (the maximum operating temperature) and to compensate for heat losses to the atmosphere within the preheater (Appendix 11.2.2). A 28-AwG (American wire gauge) molybdenu'n resistance heating element, wrapped around the last 6 in. of the outside wall of the inner preheater tube, provides this heat (Figs. 4 and 5). This constriction allows the molybdenum elenient to see only a $\mathrm{H}_{2}$ atmosphere,preventing rapid oxidation at high temperature. The temperature of the preheater gas is approximately measured by a thermocouple placed in a well on the preheater wall. This temperature may be iower than the preheater gas temperature due to heat losses by radiation from the preheater wall.

Three concentric, cylindrical, alumina radiation shields reduce heat losses from the preheater (Figs. 4 and 5). In addition, thirteen diskshaped alumina radiation shields are placed normal to the axis of the preheater anterior to the heating coil (Figs. 3 and 4). These shields protect the front inlet wall of the outer casing from reaching high 


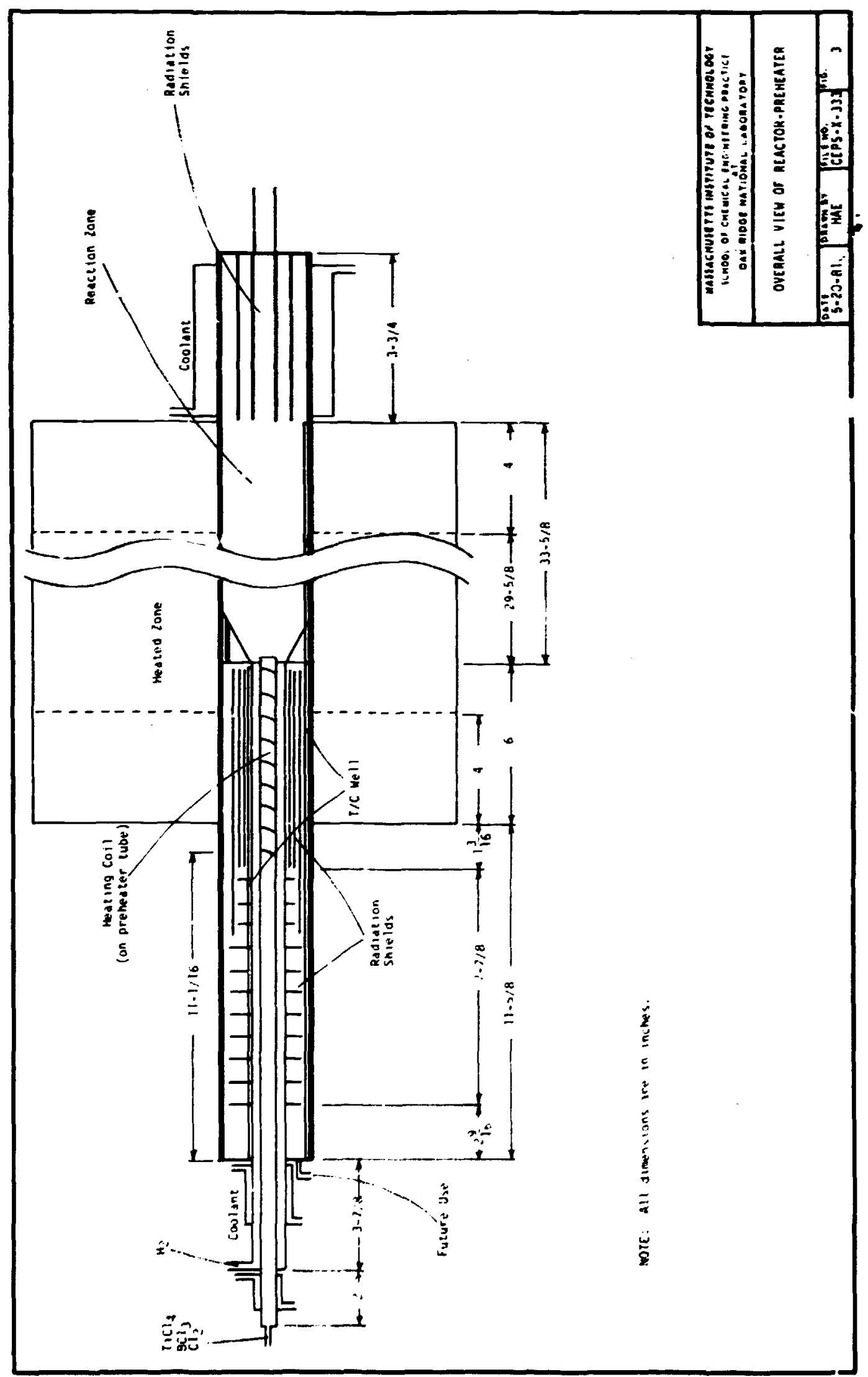




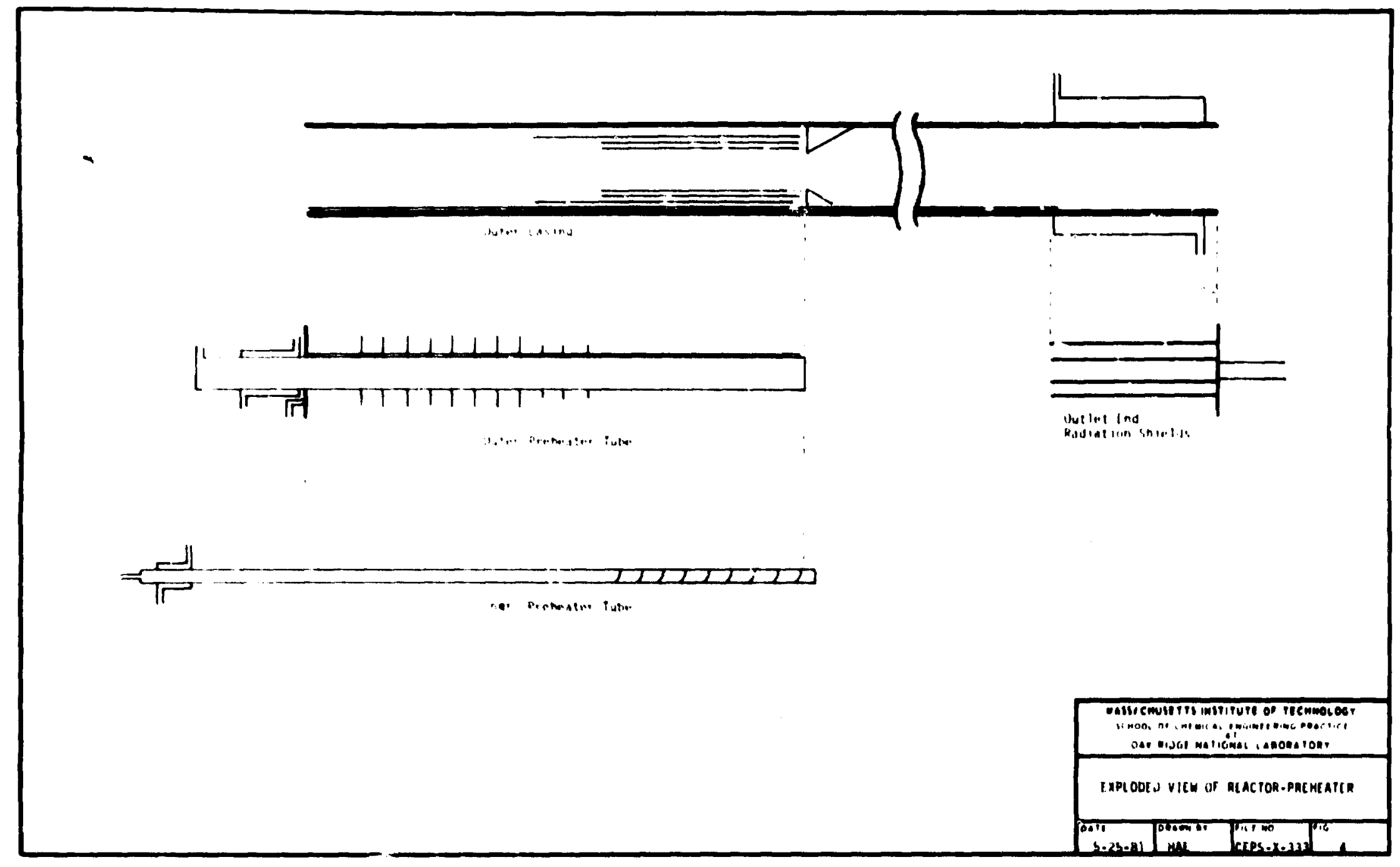

ธ. 


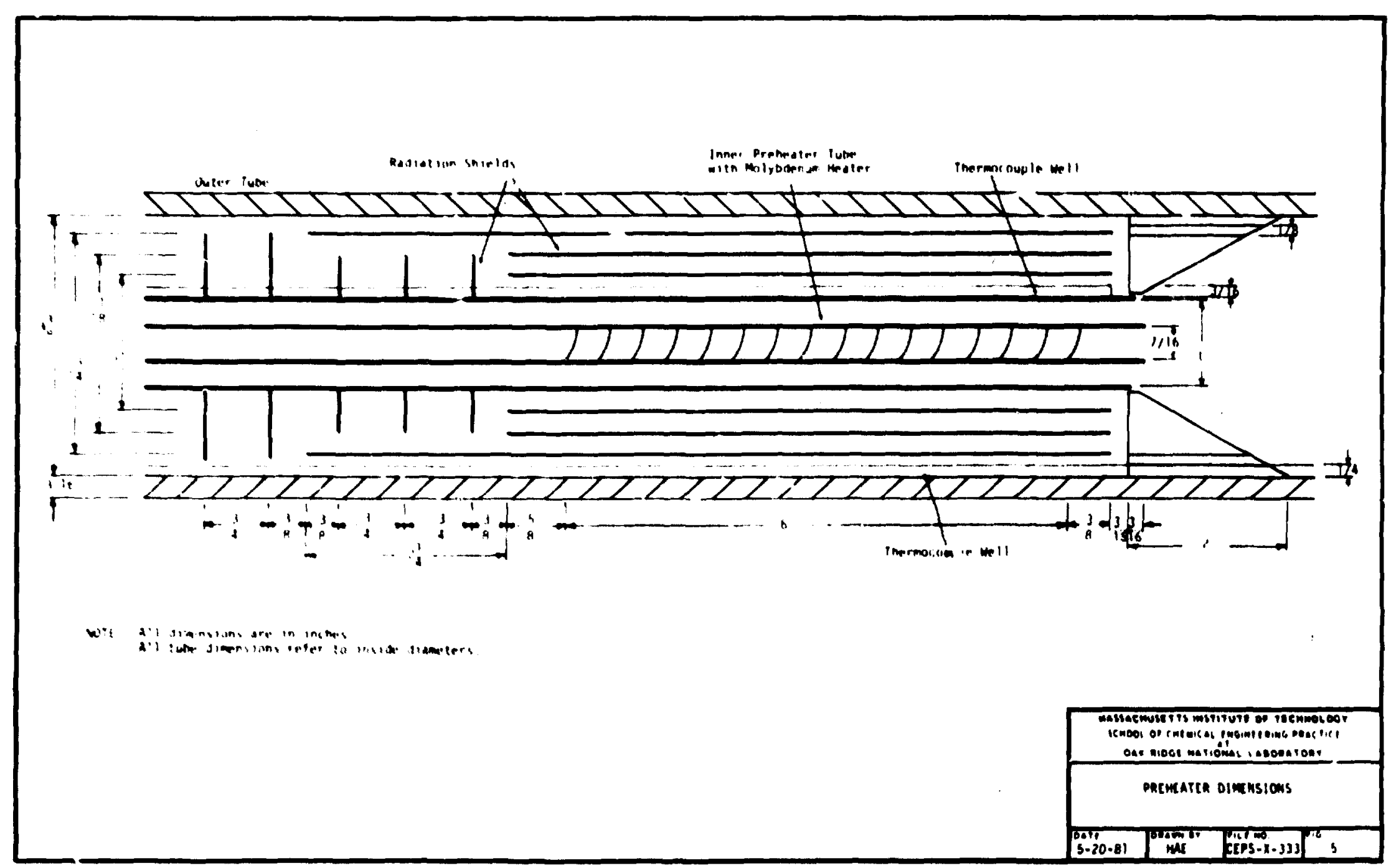


temperaturas. In addition, the outer casing is cooled by dissipating heat to the atmosphere by radiation and natural convection. This ma intains the temperature of the end wall of the outer casing below $200^{\circ} \mathrm{C}$. This low temperature is required to prevent degradation of the $V$ iton rubber vacuum seals. Cooling jackets are placed on the inner and outer preheater tubes before they enter the outer casing to ensure that their temperatures are also belon $200^{\circ} \mathrm{C}$.

The preheater itself may be dismantled and removed from the outer casing (fig. 4) and disassembled into four sections: the outer casing with a cyl indrical radiation shield and entrance cone; an outer preheater tube with the end wall of the reactor housing, thirteen disk-shaped radiation shields, and a thermocouple well; an inner preheater tube with the preheater winding and cooling coil; and finally an outlet well to the reactor housing with its four radiation shields. The two-end walls are vacuum-sealed by removable Viton rubier seals. The seals may be 0 -rings or gaskets. The specification of the final item can be relatively simple anc will take place during construction. Viton rubber is recomended for this purpose because it retains its sealing properties up to $200^{\circ} \mathrm{C}$ and will resist attack by the reactants in our system up to that temperature.

\subsubsection{Reaction Chamber}

The reacticn chamber is contained in the same outer housing as the preheater, where the outer housir.g is the outer wail of the reactor. The hydrogen stream exits the preheater tube just before the chloride stream, thus creating a hydrogen blanket between the reactor wall and the chloride stream, preventing $\mathrm{TiB}_{2}$ diffusion to the wall. This suppresses heterogeneous nucleation at the wall and enhances homogeneous nucleation in the gos phase.

A cone-shaped insert is placed i.t the reactor inlet to prevent the formation of a stagnant zone witii a backflows eddy. Details are shown in rig. 5. Holes 1/8 in. in diameter are crilled in the cone, near the outer edge, to allow evacuation of tine preheater and to provide entrance for an extra hydrogen-gas b? anket to protect the reactor wall, if necessary. This gas can be introduced into the port marked "Futire Use" (Fig. 3).

The reaction zone is $31-5 / 8$ in. long and $3-3 / 8$ in. in IU (3-7/8 in. $0 D$ ), and was sized using the kinetics of Besmann and Spear (Appendix 11.2.3). These kinetics apply for heterogeneous nucleation, and may not approximate the kinetics of homogeneous nucleation, thus the reactor was conservatively designed. The wall of the reaction zone will be maintained at a constant temperature by a tubular furnace around the reactor. The temperature inside the reactor wall will be measured by : thermocoupie in a well cemented to the inside of the reactor wall. 


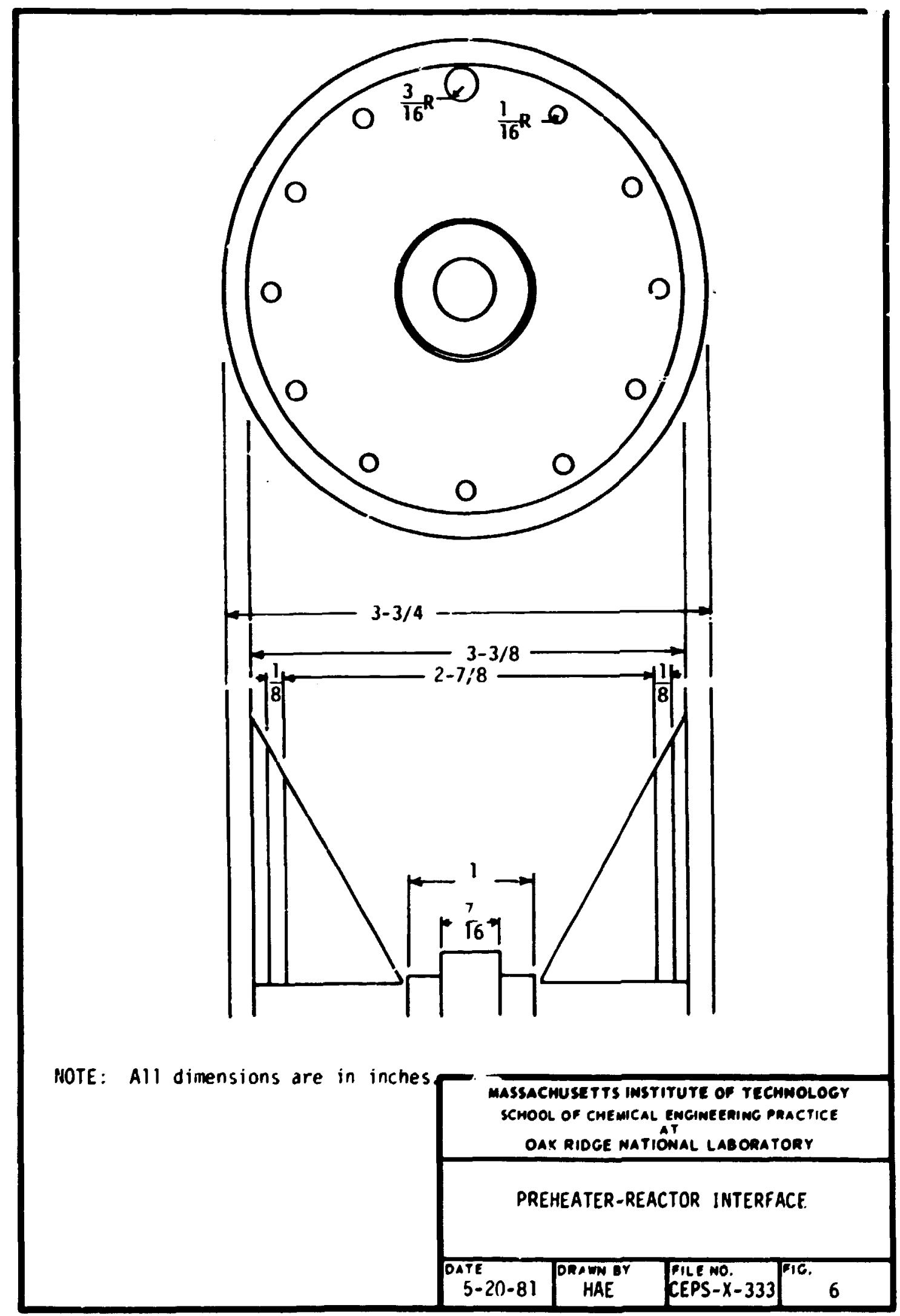


Radiation shields are placed at the outlet of the reactor to reduce the heat loss from the furnace. The shields consist of four parallel plates, 3-3/4 in. long, attached to the end plate of the outer housing (see Figs. 3 and 7). This ieactor end plate is also removable along with Yiton rubber seals; hence $a$ cooling coil is piaced on the outer casing to cool the end plate to $200^{\circ} \mathrm{C}$. This al so permits condensation of any $\mathrm{TiCl}_{3}$ which might be formed as a byproduct of the reaction onto the last $4 \mathrm{in}$. Of the casing and radiation shields. Rapid cooling of the reaction mixture also stops the reaction, thus preventing the reverse reaction from occurring.

\subsection{Reactant. Feed System}

The four reactants enter the preheater as gases. Since $\mathrm{TiCl}_{4}$ is a liquid at ambient temperature, a vaporizer must be specified. The $\mathrm{TiCl}_{4}$ vaporizer, a 1-liter stainless-steel container on a hot plate, will operate at an equilibrium pressure of $2 \mathrm{~atm}$ abs. and a temperature of $164^{\circ} \mathrm{C}$. The 1-liter volume provides sufficient $\mathrm{TiCl}_{4}$ for $10 \mathrm{~h}$ of operation while still allowing for a large vapor volume. This avoids significant pressure fluctuation of the system during vapor draw-off. The specified hot plate is rated at $800 \mathrm{~W}$ and is a standard laborato.y item.

The feed rates of the four reactant gases are controlled by bellowstype metering valves and are monitored by mass flow meters. A transducer is placed on each of the four feed lines, and the flow rates are displayed and recorded continuously. The mass flow meters offer a distinct advartage over rotameters in that they measure the mass flow rate and require no compensation for gas temperature and pressure.

Both the hyorogen and chlurine feed lines will have flash arrestors to prevent propagation of any flame in the lines and to serve as check valves. The tubing, valves, and flow transducers are specified to be 1/4-in. stainless steel with Swagelok connections. If condensation of $\mathrm{TiCl}_{4}$ should occur in the feed lines, as indicated by mass flow meter fluctuations, the feed lines will be wrapped with heating tape and insulation.

\subsection{Collection System}

It is expected that submicron size $\mathrm{TiB}_{2}$ powder will be produced. This finely divided powder is removed froil the gas stream in a $1 \mathrm{cw}-$ pressure collector. The gas streain risrying the powder exits the reactor through a regulating valve. This valve maintains the reactor pressure typically near 200 torr and the collection-system pressure near 1 torr. iwo solids collectors in parallel are used alternatively so that solids production can be monitored during continous operation. The gas/ solid product stream enters the collection trap (Fig. 8) through a tubs 


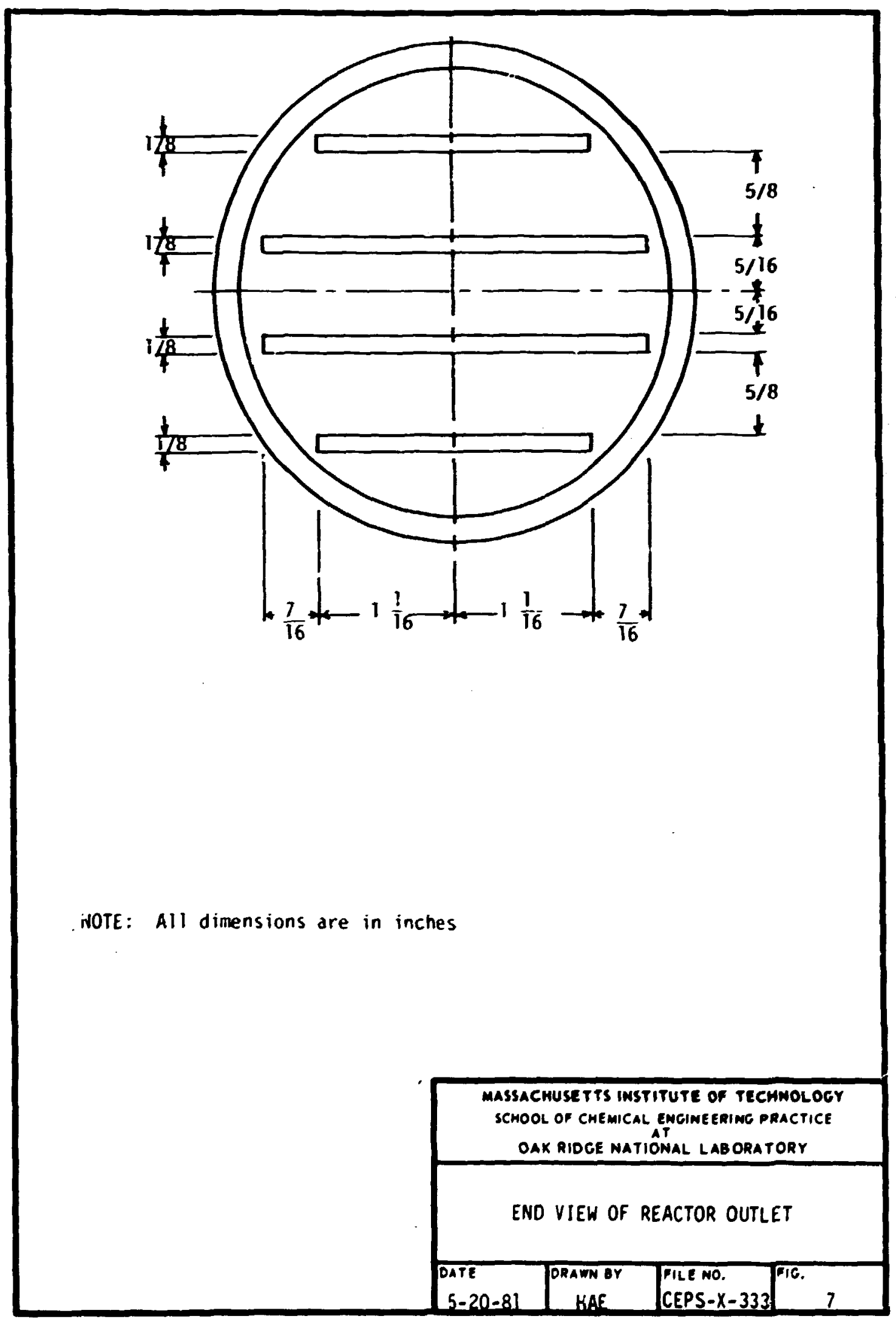


16

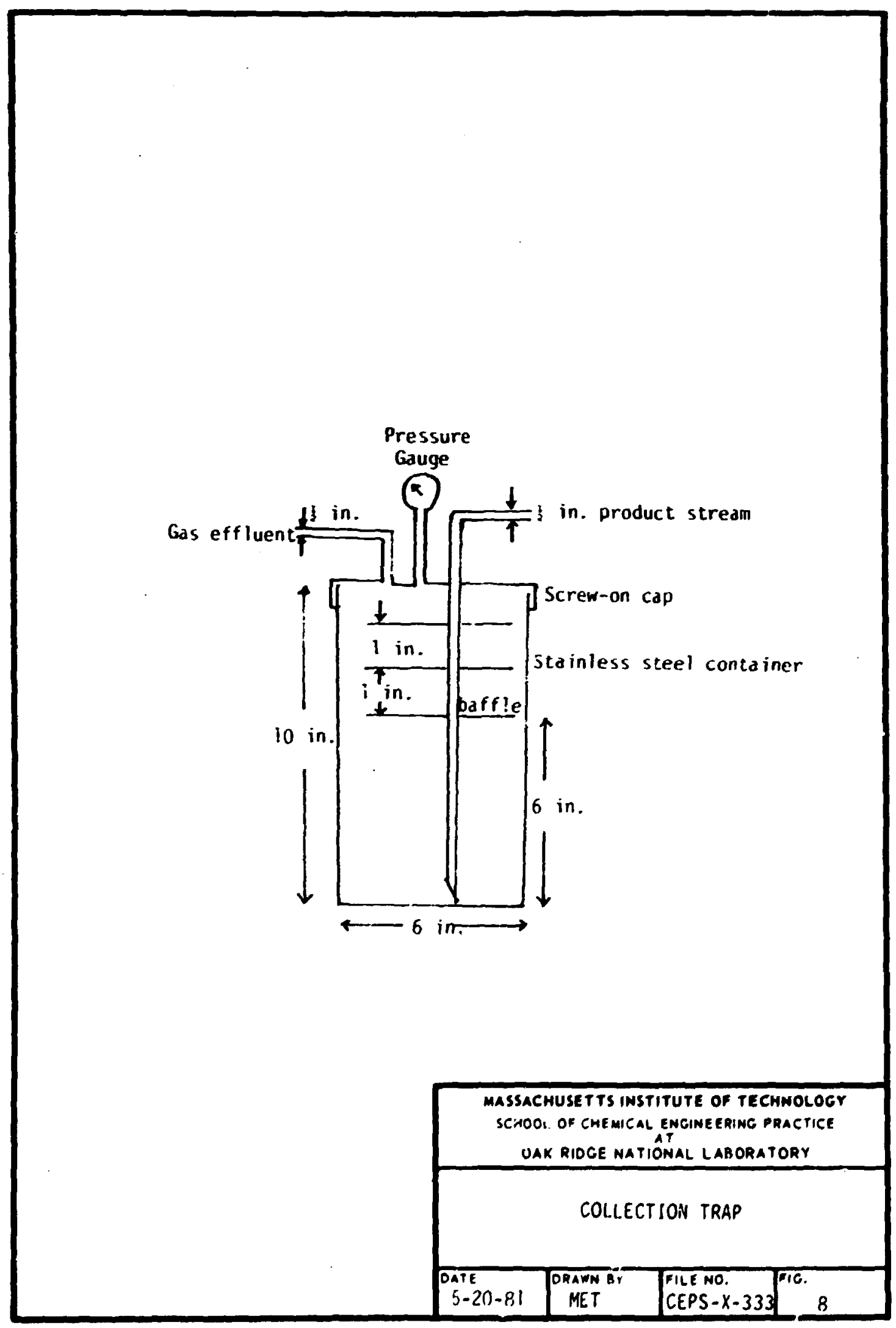


extending to the boctom of the collector. The abrupt reversal of direction of the gas strean causes deposition of the pouder by a combination of electrostatic and inertial forces. For particles in this size range, these forces become significant only if the pressure in the collectors is less than 20 torr. The exhaust gases exit through a recording mass flow meter, a vacuum pup, and another regulating valve.

A sample port, before the vacuum pump, allows gas sampling to be batch-wise with a collection bomb, or continuous using on-line instrumentation. The vacuum pum must be rated for 28001 iter/min at pressures less than 0.1 torr (Appendix 11.2.8). Two ball valves are used to iso:ate each collector and the vacuun pum or reactor during off-I ine operations concerning the collectors. A union between the two ball valves permits collector removal withoui contamination of either the reactor system or the collector. In addition, an inert-gas line can be used to overpressure each col'ector. This prevents leakage of air into the collector during transfer to a glove-box. The exit lines from the reactor are 0.5 -in.-ID stainless steel tubing connected to stai:uless steel valves with TFE packing and Swagelok fittings. Efficient soliris collection with this type of system has been demonsirated in previous studies (4).

\subsection{Exhaust-Gas Disposal System}

The exhaust gas (primarily $\mathrm{H}_{\hat{2}}$ and $\mathrm{HCl}$ ) is disposed of by absorbing the hydro en chloride in water and burning the hydrogen. The uncunverted reactants $\mathrm{TiCl}_{4}$ and $\mathrm{BCl}_{3}$ will be absorbed in the scribber. After leaving the vacuum plimp, the gases pass through a packed column witer scrubber, where the $\mathrm{HCl}$ and other water-soiuble gases are rcmoved The water flow rate of $33 \mathrm{liter} / \mathrm{h}$ gives a $0.1 \mathrm{M} \mathrm{HCl}$ effluent if the maximum amount of $\mathrm{HCl}$ is formed and absorbed. The column diameter, allowing a safety factor for plugging and flooding, is $4 \mathrm{in.}(10.2 \mathrm{~cm})$; the column height is 18 in. $(46 \mathrm{~cm})$; and the column packing is $0.5-i n$. ceramic Raschig rings (sae calculations in Appendix 11.2.7).

The absorption of $\mathrm{TiCl}_{4}$ and $\mathrm{BCl}_{3}$ is almost certainly associated with hydrolysis. Therefore fast complete absorption of these species is expected. Further study of the material balance on these compcunds will be needed when the equipment is put into operation. The scrubber exhaust, primarily hydrogen, is mixed with methane and air and is oxidized in a burner. . platinum gauze placed on top of the burner ignites the hydrogen in the event that the air/methane pilot is extinguished. The burned gases are exhausted through a fume hood.

\subsection{Utility Requirements}

The utility requirements include exhaust.-gas ventilation, cooling and scrubber water, methane for the exhaust burner, and electrical power. The $\mathrm{TiB}_{2}$ production system must be adequately ventilated in a walk-in or standard 
California fume hood. The exhaust gas is primarily air and water vapor, hence, special ventilation procedures are unnecessary; however, to ensure operator safety and to locate leaks, a chlorine detector should be installed in the hood.

Tap water can be used for cooling and scrubbing. The scrubber waste stream, mainly dilute $\mathrm{HCl}$, can be drained into a laboratory sink. Methane for the exhaust burner is available in most laboratories, or bottled gas can be used. Two electrical power lines are required: a 120-V line to operate the flow controllers, and a $230-v$ line for the vacuum pump and furnace.

\subsection{Cost Estimation}

The purchase cost of the equipment, including fabrication, is $\$ 24,500$ (May 1981 dollars, as calculated in Appendix 11.3). As shown in Table 1, the preheater-reactor system is the most expensive subsystem at $\$ 9900$.

Table 1. Cost Estimate of Equipment

\begin{tabular}{|c|c|c|}
\hline $\begin{array}{l}\text { Feeding System } \\
1 \text { metering valves } \\
4 \text { mass flow meters with recorders } \\
2 \text { flash arresters } \\
\text { vaporizer }\end{array}$ & $\$$ & 3,900 \\
\hline $\begin{array}{l}\text { Preheater-Reacior System } \\
1 \text { furnac's and controller } \\
1 \text { Varia: } \\
\text { alumina tubes and parts } \\
\text { construction }\end{array}$ & & 9,900 \\
\hline $\begin{array}{l}\text { Collection-Disposal System } \\
1 \text { vacuum pump } \\
1 \text { mass flow meter with recorder } \\
3 \text { pressure gauges } \\
\text { valves }\end{array}$ & & 8,500 \\
\hline \multirow[t]{2}{*}{ Miscellaneous Parts and Contingency } & & 2,200 \\
\hline & \multicolumn{2}{|c|}{$\$ 24,500$} \\
\hline
\end{tabular}

This will include parts and assembly,assuming that the parts are purchased ready to assemble with minimal fabrication required. Fabrication requires about 3 man-days for both an electrician and pipefitter. The feeding system costs $\$ 3900$ for the major pieces of equipment, including valves, mass flow meters, and the vaporizer. The collection and disposal syatem 
costs $\$ 8500, \$ 6000$ of which is for the vacuum pump. The remainder is for valves, pressure gauges, flow transducer, and recorder. A contingency and miscellaneousparts cost of $\$ 2200$ is included to arrive at the total of $\$ 24,500$. Additional expenses may be incurred if a fume hood is not available [\$5000 purchase cost for a 6 -ft California houd, plus $\$ 2500$ for installation (3)], or if a $240-V$ power line is not available [ $\$ 500$ purchase cost for a transformer (3)]

Operating cost, excluding labor, is estimated from the feed-material cost, as show in Table: . The operating cost for a hundred $8-h$ runs at the design flow rate is $\mathbf{6 5 4}$ (ultra-high-purity chlorine) or $\$ 7505$ (research-grade chlorine). Ultra-high-purity chlorine is much less expensive, with a minimal loss in purity (99.96\% vs $99.9 \%$ ). The cost per $8-h$ run, crediting the excess feed materials, is $\$ 42.96$ (ultra-high purity) or $\$ 70.39$ (research grade).

Table 2. Cost of Reactants

(One hundred 3-h runs)

\begin{tabular}{|c|c|c|c|}
\hline \multirow{2}{*}{$\begin{array}{l}\text { Feed } \\
\mathrm{H}_{2} \text { (Matheson purity) }\end{array}$} & Unit Size/Unit Quantity & \multirow{2}{*}{$\frac{\text { Total Cost }}{\$ 2244.00}$} & \multirow{2}{*}{$\frac{\text { Cost/Run }}{\$ 21.23}$} \\
\hline & $215 \mathrm{ft}^{3}$ & & \\
\hline $\mathrm{BC}_{3}$ & $100 \mathrm{lb}$ & 1325.00 & 11.45 \\
\hline $\mathrm{TiCl}_{4}$ & $1.5 \mathrm{~kg}$ & 936.10 & 9.04 \\
\hline 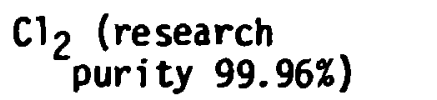 & 1001 iter & 3000.00 & 28.67 \\
\hline $\begin{array}{l}\mathrm{Cl}_{2} \text { (ultra-high } \\
\text { purity } 99.9 \% \text { ) }\end{array}$ & $151 \mathrm{~b}$ & .49 .00 & 1.24 \\
\hline Total (research $\mathrm{Cl}_{2}$ ) & & $\$ 7505.10$ & $\$ 70.39$ \\
\hline Total (ultra-high $\mathrm{Cl}_{2}$ & & $\$ 4654,10$ & $\$ 42.96$ \\
\hline \multicolumn{4}{|c|}{$\begin{array}{l}\text { NOTES: All materials will be gases purchased from Matheson, except } \\
\text { TiCl }_{4} \text {, which is a liquid and purchased from Aldrich. } \\
\text { Each run will use the design flow rate of gases, assuming that } \\
\text { one hundred } 8-h \text { experiments are completed. }\end{array}$} \\
\hline
\end{tabular}




\section{OPERATING DETAILS OF THE SYSTEM}

\subsection{Procedure}

To ensure operation safety and product purity, care must be taken during system startup and shutdown. To start up the system all the valves except the feed valves and those on the inert-gas lines are fully ofened. The vacuum pump is then started to evacuate the system. Next, the methane flow is started and the exhaust burner lit. Then the scrubber and coolingjacket water flows are started. This must be done before any heat is applied to the system to avoid damage to the vacuum seals. The furnace is then started, along with the $\mathrm{H}_{2}$ feed and preheater. Hydrogen must be flowing whenever the preheater is hot to prevent rapid oxidation of the wire by any oxygen that might be present.

Once the entire system is up to temperature, one of the two coliection traps is isclated from the system to prevent contamination during startup; then the feeds are started. The regulating valve on the outlet of the reactor should be adjusted to the desired reactor pressure. Overheating and melting of the reactor wall cannot occur because the heat losses through the reactor wall are much greater than the heat of reaction of $\mathrm{H}_{2}$ and $\mathrm{Cl}_{2}$ (Appendix 1!.2.4). Finally, the $\mathrm{TiCl}_{4}$ and $\mathrm{BCl}_{3}$ flow are adjusted to the desired feed rates. When the system is at steady state, the collection traps are interchanged. Pure TiB, now collects in the fresh trap and the contaminated trap can be cleaned for later use. To prevent pressure surges in the system, a fresh coilection trap should be first opened to vacuum, then opened to the reactor and the second trap isolated from the reactor and evacuated to remove gaseous impurities. The collector is ther isolated from the vacuum pump and slightly overpressured with argon. Thus, a small leak in the system will result in an argon outflow from the collector, preventing contamination. It is imperative that the $T i B_{2}$ powder never be exposed to air. It is probably pyrophoric. Once isolated, the collector can be placed in a glove box with an argon atmosphere for examination and testing.

System shutdown is essentially the opposite of startup. The $\mathrm{TiCl}_{4}$ $\mathrm{BCl}_{3}$, and $\mathrm{Cl}_{2}$ feeds are stopped. The preheater is turned off and allowed to cool along with the reactor furnace. When the system is near room temperature, the cooling-jacket water, vacuum pump, and hydrogen are shut off. The vacuum pump, sol ids collectors, and reactor are isolated and overpressured with argon to prevent contamination from the atmosphere. The reactor is isolated, the scrubber water and burner gas are stopped, and the solids collectors removed. If it is necessary to clean $\mathrm{TiCl}_{3}$ from the reactor, the argon flow may be stopped and the reactor opened, but only after the system is thoroughly cooled.

since it takes a great deal of time to heat up the reactor wall furnace (up to $8 \mathrm{~h}$ ), an aiternate partial shutdown procedure should be used if the system is to be used in the next couple of days. All systems can 
be shut down except the furnace. To do this, chlorine feeds and preheater should be shut down as before, keeping the hot molybdenum wire under an argon atmosphere. The scrujber water and burner gas are stopped, but the cooling-jacket water must be left on to prevent possible damage to the vacuum seals. The vacuum pump may be kept running to remove any impuricies from the system, or it may be shut off if an argon overpressure exists. System startup time would be greatly reduced during subsequent experimentation. This method prevents impurities from accumulating during shutdown, thus reducing the possibility of contamination.

\subsection{Safety Considerations}

The safety hazards in this system fall into two categories: the flammability of the reactants and the toxicity of the reactants and products. Hydrogen is very flammable, so care is required during handling. The large excess of $\mathrm{H}_{2}$ used in the reaction is burned before it is released to the atmosphere. For safety, a platinum gauze is placed before the burner head to ignite the $\mathrm{H}_{2}$ if the burner flame is extinguished. In addition, an air flow rate through the hood of greater than $1.1 \mathrm{cfm}$ would rapidly dilute the $\mathrm{H}_{2}$ siream to below its lower explosive limit of $4.1 \%$ if the gauze failed to ignite it. As a worst case, this assimes that none of the $\mathrm{H}_{2}$ reacts and all of it goes through the system into the hood. Check valves and flash arresters are placed on the $\mathrm{H}_{2}$ and $\mathrm{Cl}_{2}$ feed lines to protect the gas feed cy? inders.

Hydrogen chloride and $\mathrm{Ci}_{2}$ are both very toxic, so the entire apparatus must be placed in a fume hood. Escaping $\mathrm{HCl}$ can be detected before it causes serious harm. The odor of $\mathrm{Cl}_{2}$ can be detected at above $3.5 \mathrm{ppm}$, and there is no immediate danger until the concentration reaches $15 \mathrm{ppm}$ (11). At $15 \mathrm{ppm}$ minor throat irritation occurs, while in the range of $30 \mathrm{ppm}$, coughing begins. The maximum chlorine concentration which can be breathed for $30 \mathrm{~min}$ without damage is $4 \mathrm{ppm}$. A level of 40-60 ppm is quite dangerous if breathed for $30 \mathrm{~min}$, and $1000 \mathrm{ppm}$ is fatal after a few breaths. These dosages are a concern only if a number of rircumstances combirie to cause a disaster. Certainly no experiment should be attempted without the hood running or with known system leaks.

The major problems are associated with concentrations between 1.0 and $3.5 \mathrm{ppm}$ Chrolic exposure to greater than $1 \mathrm{ppm}$ day after day will cause damage. Since this low concentration is below the odor threshold, a chlorine detector should be placed in the roum. A continuous sampling system would be the best; however, Matheson offers a manual system which detects concentration of chlorine below 1 ppm. During startup, sampling should be frequent. Subsequently, chlorine should be monitored every few hours since short exposures to low concentrations will not cause harm. Boron trichloride is corrosive but is considered much less toxic than $\mathrm{Cl}_{2}$ (11). If the precautions discussed here are followed, there should be little danger to the operator. However, as a general precaution, two operators should be available for the startup phase of the experimental program. 


\section{6. - PROPOSED EXPERIMENTAL PLAN}

An experimental program to begin investigation is discussed below. The optimal conditions of temperature and pressure for powder formation should first be investigated. After locating the range of temperature and pressure over which powder is formed, the kinetics of the homogeneous nucleation can be studied by observing the effects of temperature, pressure, feed rates, and feed compositions on the mole \% conversion and morphology of the powder. The mole \% conversion to $\mathrm{TiB}_{2}$ solid is defined as:

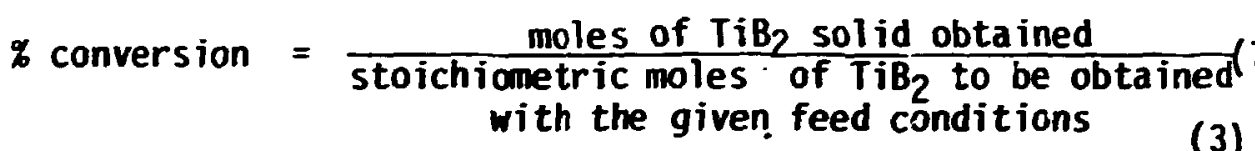

The moles of powder produced is determined by weighing the collection traps and using neutron-activation to determine the $\mathrm{TiB}_{2}$ composition of the solid. It is possible that some of the $\mathrm{TiB}_{2}$ deposits $n$ the walls and other parts of the reactor system. This occurrence may be checked by a material balance on the reactants. A proposed experimental plan along with expected results from adjustment of the variables is presented in the following sections.

\subsection{Oftimal Conditions for Powder Formation}

\subsubsection{Temperature}

The initial experiments are at constant pressure $(0.3 \mathrm{~atm})$ and different temperatures, ranging from 1200 to $1700 \mathrm{~K}$. The expected rate of $\mathrm{TiB}_{2}$ powder production, defined as the nass of $\mathrm{TiB}_{2}$ powder collected in the collection trap per unit time (constant feed rate and composition), is plotted versus reciprocal temperature in Fig. 9a. The change in slope of the curve as temperature increases is due to a change in the ratecontrolling mechanism. This behavior has been observed by Besinann for the case of heterogeneous nucleation (1), and we believe that homogeneous kinetics should follow similar behavior, except during initial formation of nuclei. A.t low temperatures, the reaction is kinetically limited, exhibiting a high activation energy (steeper slope); while at high temperatures, it becomes mass-transfer limited, exhibiting a lower activation energy. The temperature at which the transition between the two ratecontrolling mechanisms occurs, however, may be different from that for the heterogeneous kinetics observed by Besmann. The production rate of $\mathrm{TiB}_{2}$ is expected to approach a maximum with increasing temperature. This represents the optimal operating temperature. 


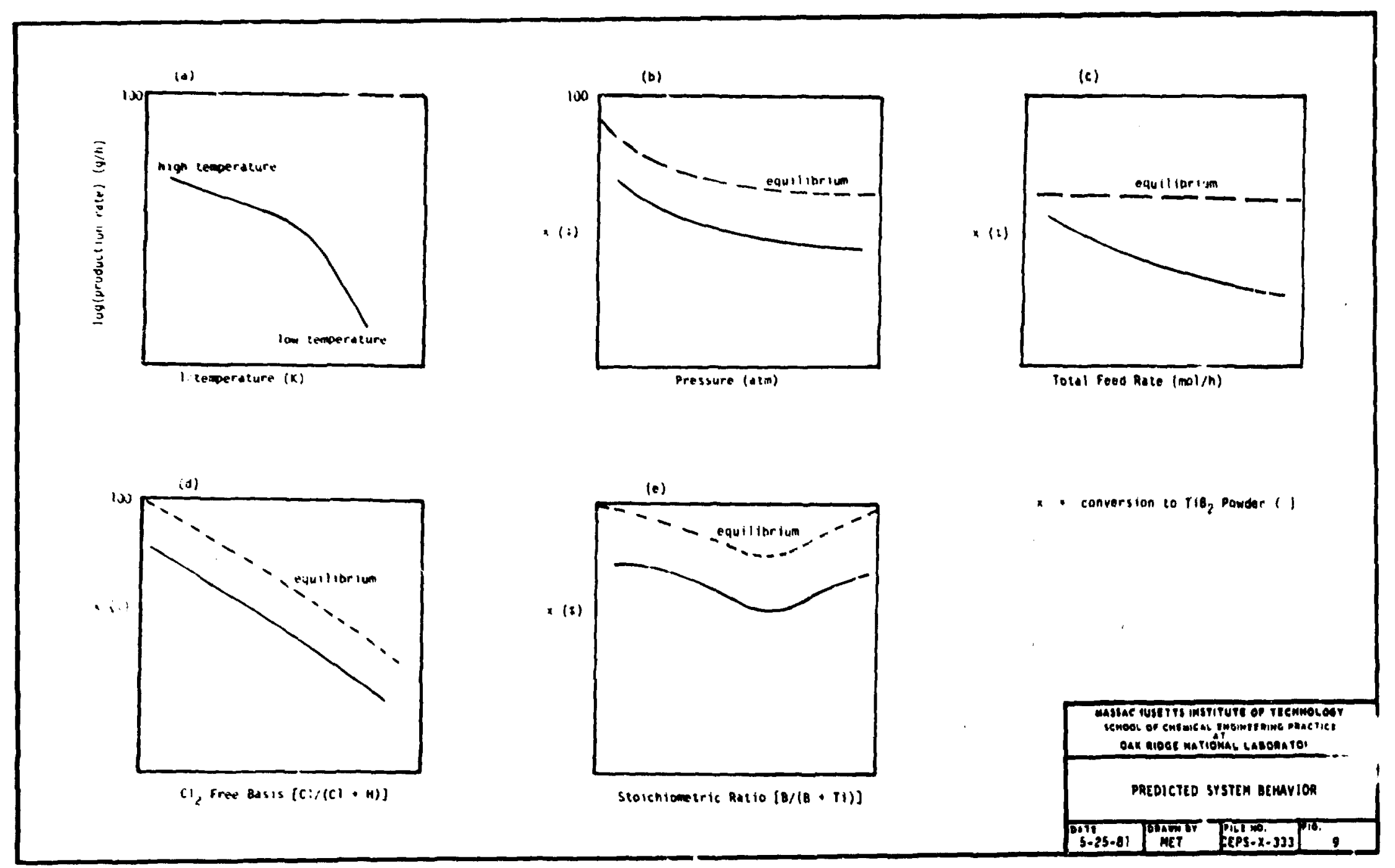


However, if no or very little powder is formed in the range 1200-1700 $K$, the solids are likely forming on the reactor wall, which is kept at the same temperature as the preheater temperature. The experiments should de repeated ovc- the same temperature range, but at a lower reactor wall teaperature than that of the preheater, thus reducing the possibility of solids being formed on the wall. However, care should be exercised that the flame not be extinguished through heat loss to the wall by radiation. The extinction of the flame can be observed as a surge of $\mathrm{Cl}_{2}$ in the product stream as measured by the in-line sampling cort. To ensure flame ignition, a thin Pt wire should be installed at the tip of the preheater. If solid $\mathrm{TiB}_{2}$ formation on the reactor wall persists after cooling the furnace, a blanket of hydrogen should be passed adjacent to the reactor wall through the opening in the reactor cone. This will deter the diffusion of re actants to the wall, suppressing heterogeneous nucleation.

After collection, the powder should be examined under a scanning eiectron microscope (SEM) to study its morphology as a function of temuerature. As temperature increases, the particles are expected to increase in size as a result of the faster reaction rate and growth rate.

\subsubsection{Pressure}

Once an optimal temperature range has been established, pressure should be varied in the range of $0.01 \mathrm{ts} 0.3 \mathrm{~atm}$. Figure $9 \mathrm{~b}$ shows a plot of expected trend of mole \% conversion to $\mathrm{TiB}_{2}$ as a function of pressure at a given temperature, feed rate, and composition. The percentage conversion decreases with increasing pressure as predicted from thermodynamics. The upper dasheo curve in Fig. $9 \mathrm{~b}$ shows the corresponding behavior of the equilibrium conversion.

Again, the morphology of the powder should be examinad ty SEM as a function of pressure, even though pressure has not been iound to affect the morphology of chemical-vapor-deposited TiB2 significantly (2).

\subsection{Kinetics Study}

The preliminary scoping experiments should be followed by a study of the kinetics of the homogeneous reaction as a function of the system variables. A statistical experimental design should be used to increase statistical reliatility while reducing the total number of experiments necessary.

The effects of temperature and pressure on the conversion have been ciscusied previously, so only the effects of feed rate and composition will be discussed here. All variables should be kept constant or adjusted systematically to isolate the particular variable being studied. Finally. a mass balance should be used to check the kinetic data obtained. 


\subsubsection{Total Feed Rate}

Figure 9c shows a plot of conversion as a funition of total feed rate for a given feed composition at constant ten rature and pressure. Conversion should decrease with increasing feed ince due to a shorter residence tikic in the reactor, although overall pouder production ray increase.

The total feed rate is also believed to affect the morphulogy of the powder. The mean particle diameter decreases as residence time decreases, thus allowing less time for partic le growth. This was observed by Formenti et ai. for metal oxide particles prepared in a hydrogen-oxygen flame (ㅁ).

\subsubsection{Feed Composition}

Feed compositions can be characterized by the $\mathrm{Cl}_{2}-$ to $-\mathrm{H}_{2}$ feed ratio $\left[\mathrm{Cl} /\left(\mathrm{Cl}+\mathrm{H}_{.}\right)\right]$and boron-to-titanical feed ratio $[\mathrm{B} /(\mathrm{B}+\mathrm{Ti})]$. The effect of feed composition is studied by changing one of the ratios and keeping the other constant.

Figure 9d shows the variation of conversion versus $\mathrm{Cl} /(\mathrm{Cl}+\mathrm{H})$ ratio in the feed. It should be noted that the ratio is defined on a gaseous$\mathrm{Cl}_{2}$-free basis since $\mathrm{Cl}_{2}$ gas in the feed participates in the overall reaction only to the extent that the flame it produces provides heat. As excess hydrogen in the feed decreases $\mathrm{Cl} /(\mathrm{Cl}+\mathrm{H})$, the reaction will be shifted towards higher conversion to $\mathrm{TiB}_{2}$.

The $\mathrm{Cl} /(\mathrm{Cl}+\mathrm{H})$ ratio affects the morphology of chemical-vapor-deposited $\mathrm{TiB}_{2}$, as observed by Besmann (2). The effect of this ratio on homogeneously produced $\mathrm{TiB}_{2}$ should be made experimentally.

Figure ge shows a plot of the conversion versus $B /(B+T i)$ feed ratio. At either $l \mathrm{jw}$ or high $B /(B+T i)$ feed ratio, conversion is high because of the excrss $\mathrm{TiCl}_{4}$ or $\mathrm{BCl}_{3}$, which shifts the equilibrium toward formation of dibori, $:$. The stoichiometric ratio, corresponding to a value of $2 / 3$, gives the lowest conversion.

The $B /(B+T i)$ ratio als) zffects the morphology of CVD $\mathrm{TiB}_{2}$ (2) in the heterogeneous case. Although conversion is minimized at the stoichiometric ratio, it is important that impurity, especially boron, be avoided. Therefore, it is recommended that at least initially the stoichionetric ratio $(2 / 3)$ be maintained.

\subsubsection{Mass Balance Calculation}

A product-gas flow meter and a sampling port, along with the feed-gas flow meters. permit calculation of an overall mass balance as well as individual-component balances. An overall mass balance on the system at the end of an experimental run gives:

$$
\begin{gathered}
\text { mass of gases } \\
\text { feJ in }
\end{gathered}=\begin{aligned}
& \text { mass of gases } \\
& \text { leaving the } \\
& \text {,ystem }
\end{aligned}+\begin{gathered}
\text { total mass c } \tilde{r} \text { solids } \\
\text { deposited }
\end{gathered}
$$


where the total mass of solids deposited is that collected in the collection trap and that deposited on the reactor wall, tubes, and valves.

Based on the material balances, the mass of solids deposited on the reactor wall, tubes, and valves can be easily determined. A collection efficiency can be defined as:

$$
\begin{aligned}
& \text { col lection efficiency } \\
& \text { of powder formation }
\end{aligned}=\frac{\text { mass of solids collected in trap }}{\text { total mass of solids obtained }}
$$

and a purity efficiency can be defined as:

$$
\text { purity efficiency }=\frac{\text { mass of } \mathrm{TiB} \text { collected }}{\text { mass of total solid collected }}
$$

The mass of solids deposited can be determined by dismantling the reactor system and weighing the parts that come in contact with the reaction mixture. One potential problem, however, is that $\mathrm{TiCl}_{3}$ collected on cold spots of the reactor wall and tubing may hydrolyze to give $\mathrm{HCl}$ and oxychlorides when exposed to moist air (10). This could introduce error in the mass balance. A component mass balance on the gaseous species at steady state provides an estimation of the reaction rates of individual gaseous species. From these balances, reaction rates can be followed as a function of changes in temperature, pressure, feed rates, and feed compositions, as described in the previous section.

\section{PRODUCT ANALYSIS}

Once the $\mathrm{TiB}_{2}$ powder is obtained, it must be analyzed for purity and crystal morphology. The following discussion describes the purity analysis. The most accurate method, and for some elements the only method of analysis, is by neutron activation (NA). The sample is bombarded with neutrons to form unstable isotopes whose decay enernies are monitored. In this way almost any solid element can be detect to the ppm range. Two important impurities which may be present are oxyycn and chlorine. $\mathrm{TiCl}_{3}$ is formed along with the $\mathrm{TiB}_{2}$; however, it is not known to what extent the trichloride is formed. $\mathrm{TiCl}_{3}$ can be sublimed above $425^{\circ} \mathrm{C}$ to purify the $\mathrm{TiB}_{2}$; but, to determine reaction kinetics, it is importart to measure the conversion to $\mathrm{TiCl}_{3}$. This is convenientiy done using neutron activation. Oxides of titanium and taron, impurities which weaken $\mathrm{TiB}_{2}$ grain boundaries, can be detected by neutron activation only. Characterization and control of these impurities is critical if high-strength $\mathrm{TiB}_{2}$ is to be produced.

Samples to be analyzed by neutron activation should be stored under $\mathrm{N}_{2}$. Argon, the collection trap atmosphere, emits radiation upon neutron activation. Solid samples may be transferred from a glove box to a small 
sample vial and analyzed. Care must be taken during handling because the powder is pyrophoric; however, cnce placed in a sample vial it is never removed during analysis. Lamont Bate, at the High Fl'sx Isotope Reactor, is familiar with $\mathrm{NA}$ analysis of $\mathrm{TiB}_{2}$.

Another andlytical technique is Scanning Electron Microscopy (SEA). Chlorine can be detected by this method; however, oxygen cannct. To achieve a quancitative estimate of the composition, standards of pure $\mathrm{TiB}_{2}$ with known amounts of ch!oride must be prepared and then compared with an unknown sample. This method offers two advantages over neutron activation. It can be conducted in conjunction with examination of the morphology, and it is much less expensive than neutron activation. SEM indicates which species are present (atomic number greater than sodium) and approximate compositions.

\section{CONCLUSIONS}

A reactor system was designed to produce $\mathrm{TiB}_{2}$ powder at the rate of $4 \mathrm{~g} / \mathrm{h}$ directly by homogeneous nucleation. The production can be optimized by examining the $\mathrm{TiB}_{2}$ powder properties, morphology, and compactinn behavior as reaction conditions are changed. The system is expected to cost $\$ 24,500$ to build.

\section{RECOMENDATIONS}

1. An accurate method for measuring reaction gas and flame temperature should be found in order to allow better understanding of the reaction kinetics.

2. If higher linear velocities are needed in the gas streams exiting the preheater, flame-burner jets can be made, using capped preheater tubes with drilled orifices.

3. If corrosion of the vacuum pump occurs, a cold-trap, using liquid nitrogen, can be installed before the pump to trap most of the corrosive gases. This is not expected to be a problem.

4. To minimize heterogeneous nucleation, a porous shell tube may be installed inside the reaction chamber so that excess hydrogen can be passed through the shell to diffuse into the center of the chamber, thus blanketing the reactor wall from the reactants.

5. Plasma enhancement using an RF induction coil may be added to the proposed design to electronically excite the gases without heating them, thus increasing reaction kinetics at lower temperature. 


\section{ACKNOULEDGHERTS}

We thank our consultants, Jorulf Brynestad, Carlos Bamberger, and Richard Heestand, for their help and guidance througheut the project. We also thank the following for their help: Theodore Besmann for his help on the theory behind tive reaction, Eabell Finch for his help on the solids analysis, and Earnest Earley for his help with the equipment costing. 


\section{APPENDIX}

\subsection{Thermodynamic Properties of the Components}

Thermodynamic properties for all chemical species involved in the reaction are given in Table 3 at $1700 \mathrm{~K}$. Since the reaction is carried out at reduced pressures and elevated temperatures, ideal gas behavior may be assumed for all gaseous components.

Table 3. Thermodynamic Properties of Chemical Species (16) $T=1700 \mathrm{~K}$

\begin{tabular}{|c|c|c|c|c|}
\hline Species & $\begin{array}{c}c_{p} \\
(c a 1 / m o l-K)\end{array}$ & $\begin{array}{l}\mathrm{H}^{\circ}-\mathrm{H}_{298}^{\circ} \\
(\mathrm{kcal} / \mathrm{mol})\end{array}$ & $\begin{array}{c}\Delta H_{f} \\
(\mathrm{kcai} / \mathrm{mol})\end{array}$ & $\begin{array}{c}\Delta G_{f} \\
(\mathrm{kcal} / \mathrm{mol})\end{array}$ \\
\hline $\mathrm{TiCl}_{4}(\mathrm{~g})$ & 25.72 & 35.38 & -183.02 & -133.31 \\
\hline $\mathrm{TiCl}_{3}(\mathrm{~g})$ & 20.45 & 28.14 & -130.54 & -108.34 \\
\hline $\mathrm{TiB}_{2}(\mathrm{~s})$ & 21.60 & 25.09 & -68.90 & -59.38 \\
\hline $\mathrm{BCl}_{3}(\mathrm{~g})$ & 19.58 & 26.07 & -96.85 & -75.66 \\
\hline $\mathrm{HCl}(g)$ & 8.31 & 10.61 & -22.79 & -25.09 \\
\hline $\mathrm{H}_{2}(\mathrm{~g})$ & 7.92 & 10.23 & 0.00 & 0.00 \\
\hline $\mathrm{Cl}_{2}(\mathrm{~g})$ & 9.10 & 12.44 & 0.00 & 0.00 \\
\hline
\end{tabular}

\subsection{Design Calculations}

The original design calculations and data are on file at the MIT School of Chemical Engineering Practice, B1dg. 1505, ORNL. Appendices 11.2.1 through 11.2 .8 detail the design calculations for all major equipment items.

\subsubsection{Calculation of Feed Flow Rates}

This system was designed to produce $\mathrm{TiB}_{2}$ at the rate of $4 \mathrm{~g} / \mathrm{h}$. Conversion limits were obtained from equilibrium data; however, since little is known of the kinetics of the homogeneous reaction, a $30 \%$ approach to equilibrium was assumed. 
An expression for the thermodynamic equilibrium constant as a function of temperature was given by Besmann and Spear (1) for the reaction:

$$
\mathrm{TiCl}_{4}(\mathrm{~g})+2 \mathrm{BCl}_{3}(\mathrm{~g})+5 \mathrm{H}_{2}(\mathrm{~g}) \rightleftarrows \mathrm{TiB}_{2}(\mathrm{~s})+10 \mathrm{HCl}(\mathrm{g})
$$

the equilibrium constant is:

$$
K=\frac{\left(P_{\mathrm{HCl}}\right)^{10}}{\left(P_{\mathrm{TiCl}_{4}}\right)\left(P_{\mathrm{BCl}}\right)^{2}\left(\mathrm{P}_{\mathrm{H}_{2}}\right)^{5}}=P_{\text {tot }}^{2} \frac{\left(x_{\mathrm{HCl}}\right)^{10}}{\left(x_{\mathrm{TiCl}_{4}}\right)\left(x_{\mathrm{BCl}}\right)^{2}\left(x_{\mathrm{H}_{2}}\right)^{5}}
$$

where $P$ is the pressure in atm, and $x$ is the mole fraction.

Besmann and Spear (1) report that the equilibrium constant is:

$$
-1(K)=31.32-\frac{35,300}{T}
$$

where $T$ is in degrees Kelvin. At $1700 K$ the equilibrium constant $K=$ $3.77 \times 10^{4}$.

A total pressure of $0.30 \mathrm{~atm}$ was assumed. Hydrogen is three times stoichiometric and $\mathrm{BCl}_{3}$ is stoichiometric. The following variables are defined, where $f_{1}, f_{B}$, and $f_{\mathrm{H}_{2}}$ are the molar feed rates of $\mathrm{TiCl}_{4}, \mathrm{BCl}_{3}$, and $\mathrm{H}_{2}$, respectively, and $y$ is the molar rate of removal of $\mathrm{TiCl}_{4}$.

Based on the stoichiometry of the reaction [Eq. (2)], the following flow rates prevail in the gas phase at equilibrium: $\mathrm{TiCl}_{4}=\mathrm{f}_{\mathrm{Ti}}-\mathrm{y}$, $\mathrm{BCl}_{3}=\mathrm{f}_{\mathrm{B}}-2 \mathrm{y}, \mathrm{H}_{2}=\mathrm{f}_{\mathrm{H}_{2}}-5 \mathrm{y}$, and $\mathrm{HCl}=10 \mathrm{y}$. The total liolar flow rate in the gas phase then becomes:

$$
f_{\text {tot }}=f_{T i}+f_{B}+f_{H_{2}}+2 y
$$

The equilibrium constant in terms of initial feed rates and changes in the number of moles now becomes:

$$
K=\left(\frac{P_{t o t}}{f_{T i}+f_{B}+f_{H_{2}}+2 y}\right)^{2}\left(\frac{(10 y)^{10}}{\left(f_{T i}-y\right)\left(f_{B}-2 y\right)^{2}\left(f_{H_{2}}-5 y\right)^{5}}\right)
$$


An iterative solution of Eq. (10) is required to find $y$, the amount of $\mathrm{TiCl}_{4}$ reacted at equilibi-ium. If a basis of 1 mole/unit time of $\mathrm{TiCl}_{4}$ feed is assumed, then $y$ becomes the equilibriun conversion.

The design conditions are: $P_{\text {tot }}=0.30 \mathrm{~atm}$ abs; $f_{T j}=1.0 \mathrm{~mol} / \mathrm{h}$; $f_{B}=2.0 \mathrm{~mol} / \mathrm{h} ; f_{H_{2}}=15.0 \mathrm{~mol} / \mathrm{h} ; \mathrm{T}=1700 \mathrm{~K} ;$ and $\mathrm{K}=3.37 \times 10^{4}$. If these values are substituted into Eq. (10), the following results:

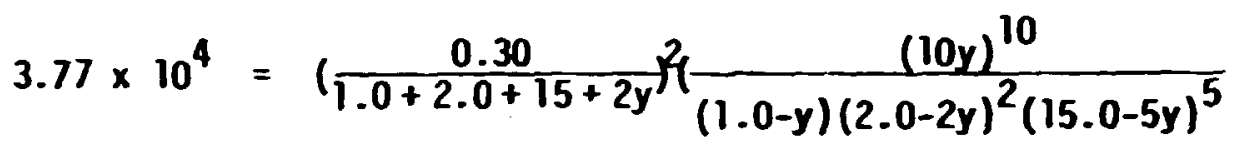

A trial-and-error solution yields:

$$
y=0.95
$$

Since a $30 \%$ approach to equilibrium was assumed, the actual conversion in our system is 0.29 .

To calculate the feed rate of $\mathrm{TiCl}_{4}$, it is assumed that no side reactions occur and that $4 \mathrm{~g} / \mathrm{h} \mathrm{TiB}_{2}$ is produced. The molecular weight of $\mathrm{TiB}_{2}$ is 69.522; hence, $4 \mathrm{~g} / \mathrm{h}$ is $0.0575 \mathrm{gmol} / \mathrm{h} \mathrm{TiB}$ produced. Based on a $29 \%$ conversion of $\mathrm{TiCl}_{4}$, and assuming no side reactions, $0.21 \mathrm{gmol} / \mathrm{h}$ of $\mathrm{TiCl}_{4}$ will be required.

A stoichiometric amount of $\mathrm{BCl}_{3}$ is $0.42 \mathrm{~mol} / \mathrm{h}$, and a three-times molar excess of $\mathrm{H}_{2}$ is $3.20 \mathrm{~mol} / \mathrm{h}$.

Chlorine will be added to provide the heat of reaction for the production of $\mathrm{TiB}_{2}$, as required by reactions (11) and (12):

$$
\begin{aligned}
& \mathrm{TiCl}_{4}(\mathrm{~g})+2 \mathrm{BCl}_{3}(\mathrm{~g})+5 \mathrm{H}_{2}(\mathrm{~g}) \rightarrow \mathrm{TiB}_{2}(\mathrm{~s})+10 \mathrm{HCl}(\mathrm{g}) \\
& \Delta \mathrm{H}_{\text {ryn }}=80 \mathrm{kCal} \text { at } 1700 \mathrm{~K} \\
& \mathrm{H}_{2}(\mathrm{~g})+\mathrm{Cl}_{2}(\mathrm{~g}) \longrightarrow 2 \mathrm{HCl}(\mathrm{g}) \\
& \Delta \mathrm{H}_{\text {rxn }}=-45.5 \mathrm{kcal} \text { at } 1700 \mathrm{~K}
\end{aligned}
$$

The $\mathrm{TiB}_{2}$ reaction was assumed with a conversion of 0.29 , while the $\mathrm{HCl}$ reaction is assumed to have a conversion of 1.0. For each mole of $\mathrm{TiCl}_{4}$ fed, $23.2 \mathrm{kcal}$ of heat is required $(0.29 \times 80 \mathrm{kcal})$. Therefore, $23.2 / 45.5$ or 0.51 mole of $\mathrm{Sl}_{2}$ is needed per mole of $\mathrm{TiCl}_{4}$ fed. 
Thus the molar flow of $\mathrm{Cl}_{2}$ required is:

$$
(0.21 \mathrm{~mol} \mathrm{TiCl} / \mathrm{h})\left(0.51 \mathrm{~mol} \mathrm{Cl}_{2} / \mathrm{mol} \mathrm{TiCl}_{4}\right)=0.10 \mathrm{~mol} \mathrm{Cl}_{2} / \mathrm{h}
$$

Obviously 0.1 wole of $\mathrm{H}_{2}$ is added to react with the $\mathrm{Cl}_{2}$, bringing the total $\mathrm{H}_{2}$ feed rate to $3.30 \mathrm{~mol} / \mathrm{hr}$. In sumary, the feed rates for all four gases are: $\mathrm{H}_{2}, 3.30 \mathrm{~mol} / \mathrm{h} ; \mathrm{TiCl}_{4}, 0.21 \mathrm{~mol} / \mathrm{h} ; \mathrm{BCl}_{3}, 0.42 \mathrm{~mol} / \mathrm{h}$; and $\mathrm{Cl}_{2}, 0.10 \mathrm{~mol} / \mathrm{h}$.

\subsubsection{Preheater Calculations}

The physical dimensions as well as the heat duty of the preheater are calculated below. The energy required (kcal/mol) to heat the gases from 298 to $1700 \mathrm{~K}$ is show in Table 4.

Table 4. Energy Required to Heat Feed Components

\begin{tabular}{llc}
\hline Gas & $\Delta Q(\mathrm{kcal} / \mathrm{mol})$ \\
$\mathrm{TiCl}_{4}$ & 35.375 \\
$\mathrm{BCl}_{3}$ & 26.072 \\
$\mathrm{Cl}_{2}$ & 12.441 \\
$\mathrm{H}_{2}$ & 10.233 \\
\hline
\end{tabular}

The energy tr, heat the first stream, containing the $\mathrm{H}_{2}$, is:

$$
\begin{aligned}
& Q=\dot{n} \Delta Q=(3.30 \mathrm{~mol} / \mathrm{h})(10.233 \mathrm{kcal} / \mathrm{mol})=33.77 \mathrm{kcal} / \mathrm{h} \\
& \text { or } 39.26 \mathrm{~W}
\end{aligned}
$$

Similarly, the energy to heat the other stream, containing the $\mathrm{TiCl}_{4}$, $\mathrm{BCl}_{3}$, and $\mathrm{Cl}_{2}$, is:

$$
Q=\sum_{i} n_{i} \Delta Q_{i}=19.62 \mathrm{kcal} / \mathrm{h} \text { or } 22.81 \mathrm{~W}
$$

A total duty of $500 \mathrm{~W}$ will be used to account for heat losses to the atmosphere. 
The tube and annulus are sized to give equal linear velocities of the two streams when exiting the nozzle, thus reducing turbulence and eddies.

The volumetric flow rates of each gas at final conditions can be calculated from the ideal gas law:

$$
\dot{v}=\frac{\dot{n} R T}{P}
$$

The calculated volumetric flow rates for each gas at $1700 \mathrm{~K}, 0.30 \mathrm{~atm}$ is given in Table 5.

Table 5. Flow rates

\begin{tabular}{ccc}
\hline Feed Component & $\underline{\dot{n}(\mathrm{~mol} / \mathrm{h})}$ & $\underline{\dot{v}\left(\mathrm{~cm}^{3} / \mathrm{min}\right)}$ \\
\hline $\mathrm{H}_{2}$ & 3.30 & $25,587.0$ \\
$\mathrm{Cl}_{2}$ & 0.10 & 775.4 \\
$\mathrm{TiCl}_{4}$ & 0.21 & $1,628.3$ \\
$\mathrm{BCl}_{3}$ & 0.42 & 3.256 .6
\end{tabular}

If a linear velocity of $200 \mathrm{ft} / \mathrm{min}(6096 \mathrm{~cm} / \mathrm{min})$ is assumed, the total flow through the tube, which carries the $\mathrm{TiCl}_{4}, \mathrm{BCl}_{3}$, and $\mathrm{rl}_{2}$, is $5660.3 \mathrm{~cm} / \mathrm{min}$. Thus, the area of the tube AT is $0.93 \mathrm{~cm}^{2}$ or the radius is $0.54 \mathrm{~cm}$. If a tube-wall thickness of $25 \mathrm{mils}(0.0635 \mathrm{~cm})$ is assumed (12), the outer radius of the tube is $0.6035 \mathrm{~cm}$. By a similar calculation the outer tube area is $4.20 \mathrm{~cm}^{2}$, or the outside radius is $1.30 \mathrm{~cm}$, assuming a $0.0635-\mathrm{cm}$ wall thickness. For these exit conditions, tapered tubes are unnecessary since the heating wire is 28 AWG (American Wire Gauge) (14), which is $0.032 \mathrm{~cm}$ in diameter and thus will not restrict the flow. If higher linear velocities are desired, the tubes, sealed at one end, should be purchased and holes drilled in the ends of them to give a smaller area for flow; alternatively, smaller tubes can be installed if adequate residence time for heating is maintained.

The length of the preheater to be wrapped by heating coil can be calculated, assuming that heat transfer occurs from the hot preheater wall to the gas by two processes: convection and radiation. The heat transfer rate $Q$ is given by:

$$
Q=h A\left(T_{w}-T_{g}\right)+v \varepsilon A\left(T_{w}^{4}-T_{g}^{4}\right)
$$


where: $h=$ convective heat transfer coefficjent $=2.78 \times 10^{-4} \mathrm{cal} / \mathrm{s}-\mathrm{cm}^{2}-k$, $\sigma=$ Stefan-Boltzmann constant $=1.36 \times 10^{-12} \mathrm{cal} / \mathrm{cm}^{2}-\mathrm{s}-K^{4}$, and $\varepsilon=\mathrm{emis}-$ sivity $=0.4$.

The preheater is divided into small sections; a constant wali temperature is assuned for each section. The length of each section is calculated from the heat required to raise the gas temperature to the specified level. The length of the preheater is the sum of the subsection lengths. As an example, the heat duty required for the largest stream $\left(\mathrm{H}_{2}\right)$ is presented. The temperature rise in a section is $100 \mathrm{~K}$, and the average temperature over the section is used to calculate the length. Equation (16) is useo for the calculation.

$$
\begin{aligned}
Q(\text { cal } / s)= & \left(2.78 \times 10^{-4}\right) 2 \pi(0.5) L\left(1700-T_{g}\right) \\
& +\left(1.36 \times 10^{-12}\right)(0.4) 2 \pi(0.5) L\left[(1700)^{4}-T_{g}^{4}\right] \\
= & \left\{8.73 \times 10^{-4}\left(1700-T_{g} !+1.71 \times 10^{-12}\left[(1700)^{4}-T_{g}^{4}\right]\right\} L\right.
\end{aligned}
$$

The heat duty and associated length of each section of the preheater is given in Table 6 .

Table 6. Heat Duty and Preheater Length

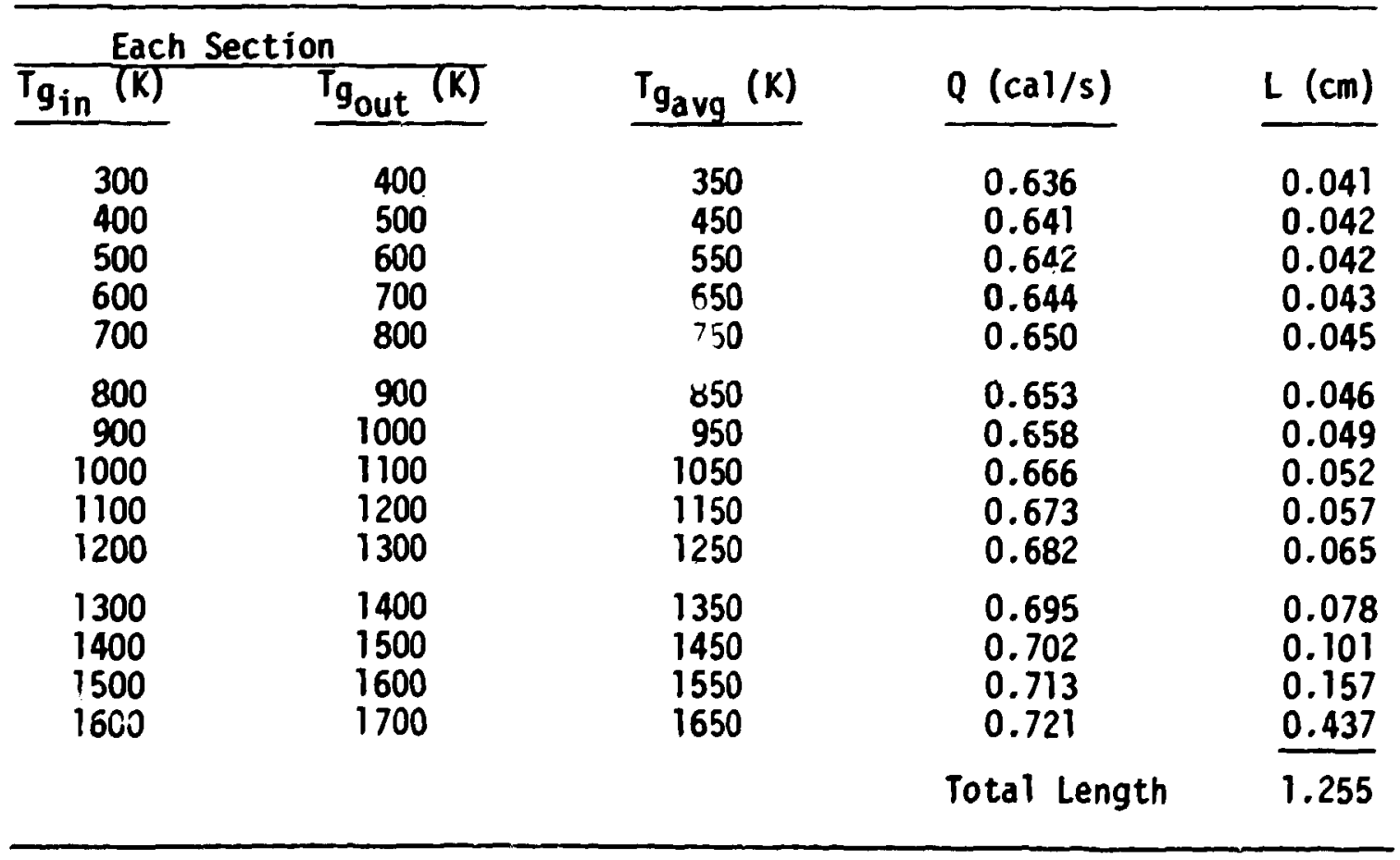


The calculation of the preheater length is, of necessity, approximace. Indeed, the temperature of the gas can only approach the $1700^{\circ} \mathrm{K}$ wall temperature. Therefore 6 in. of preheater will be wrapped with resistance wire, which will provide any additional heat requirement.

\subsubsection{Estimation of Reactor Volume}

Since very little is known about the kinetics of the homogeneous nucleation process, Besmann's reactor residence time was used to get an initial estimate of the reactor volume (1). The volume of the reactor used in the Besmann study was $43.3 \mathrm{~cm}^{3}$, and the total flow rate was $462 \mathrm{~cm}^{3} / \mathrm{min}$ (STP). At $T=1700 \mathrm{~K}$ and $P=0.3 \mathrm{~atm}$, the volumetric flow rate is:

$$
F=462\left(\frac{1}{0.3}\right)\left(\frac{1700}{273}\right)=9590 \mathrm{~cm}^{3} / \mathrm{min}
$$

and the residence time is:

$$
\tau=\frac{V}{F}=\frac{43.3}{9590}=0.27 \mathrm{~s}
$$

For the molar flow rates given in Appendix 11.2 .1 , at $T=1700 \mathrm{~K}$ and $\mathrm{P}=$ $0.3 \mathrm{atin}$, the total flow is:

$$
F=\sum_{i=1}^{4} \dot{v}_{i}=31,233 \mathrm{~cm}^{3} / \mathrm{min}
$$

From Eq. (19) the reactor voiume is calculated to be $140.5 \mathrm{~cm}^{3}$. This represents a lower limit of the reactor volume needed because homogeneous kinetics are believed to be slower than heterogeneous and thus may need a longer residence time. Thus both the reactor volume was oversized to provide adequate residence time and the furnace to minimize heat loss from the hot zone by radiation through the reactor outlet.

\subsubsection{Calculation for Heat Losses Through Furnace Wall}

Heat loss through the furnace wall was computed to determine whether it will be sufficient to dissipate the energy generated by the reaction of $\mathrm{H}_{2}$ and $\mathrm{Cl}_{2}$ if the reaction to form $\mathrm{TiB}_{2}$ does not occur. The major resistance to heat transfer is the firebrick around the furnace. The firebrick is assumed to have a circular configuration. The outside temperature of the alumina tube and the inside temperature of the firebrick are assumed to be $1500 \mathrm{~K}$. The outside temperature of the firebrick is $298 \mathrm{~K}$ with $18 \mathrm{in}$. of length. The heat transfer rate $Q$ is: 


$$
Q=2 \pi k \frac{T_{1}-T_{2}}{k\left(r_{1} / r_{2}\right)}
$$

where:

$$
\begin{aligned}
k & =0.89 \mathrm{kcal} / \mathrm{m}-\mathrm{hr}-{ }^{\circ} \mathrm{C}(14) \\
T_{1} & =1500 \mathrm{~K} \\
T_{2} & =298 \mathrm{~K} \\
r_{1} & =0.505 \mathrm{~m}(\text { firebrick 00) } \\
r_{2} & =0.048 \mathrm{~m}(\text { firebrick ID) } \\
\therefore \quad Q & =2856 \mathrm{kcal} / \mathrm{h}-\mathrm{m} \text { furnace length }
\end{aligned}
$$

Only $4.5 \mathrm{kcal} / \mathrm{h}$ of heat must be dissipated if the reaction to form $\mathrm{TiB}_{2}$ fails to occur. Thus, overheating the reactor to the melting point cannot occur under the conditions for which the unit was designed.

\subsubsection{Estimation of Theoretical Flame Temperature}

The theoretical flame temperature is the maximun temperature the flame can attain under adiabatic conditions. For the combustion of $\mathrm{H}_{2}$ in $\mathrm{Cl}_{2}$ :

$$
\mathrm{H}_{2}+\mathrm{Cl}_{2} \rightarrow 2 \mathrm{HCl} \quad \Delta \mathrm{H}_{\text {combustion }}=-45.5 \mathrm{kcal} / \mathrm{mole} \mathrm{Cl}_{2}
$$

For the design flow rates, on a $1-h$ basis, assuming no $\mathrm{TiB}_{2}$ formation, the

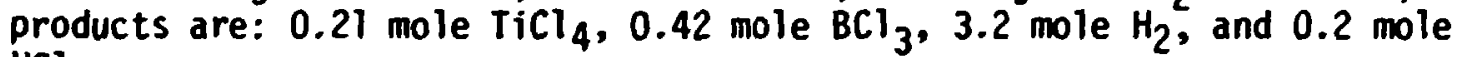
$\mathrm{HCl}$.

The energy balance becomes:

$$
\underset{\text { feed }}{\Sigma} n_{i} \bar{C}_{p_{j}}\left(T_{0}-T_{\text {ref }}\right)+n_{C l_{2} \Delta H_{\text {comb }}}=\underset{\text { proouct }}{\sum} n_{i} \bar{C}_{p_{j}}\left(T_{f}-T_{\text {ref }}\right)
$$

For $T_{0}=1700 \mathrm{~K}$ and $T_{\text {re } i}=1700$, Eq. (21) becomes:

$$
\begin{aligned}
0+(0.1)(45,500)=(0.21 & \bar{C}_{P_{T i C 1}}+0.42 \bar{C}_{P_{B C 1}}+3.2 \bar{C}_{P_{H_{2}}} \\
& \left.+0.2 \bar{C}_{P_{H C l}}\right)\left(T_{f}-1700\right)
\end{aligned}
$$


Between 1700 and $2000 \mathrm{~K}, \overline{\mathrm{C}}_{\mathrm{p}_{\mathrm{i}}}$ can be obtained from JANAF Tables (16), where $\overline{\mathrm{C}}_{\mathrm{PBCl}_{3}}$ is $19.62 \mathrm{cal} / \mathrm{gmol}-\mathrm{K}_{;} \overline{\mathrm{C}}_{\mathrm{PTiCl}_{4}}$ is $25.73 \mathrm{cal} / \mathrm{gmol}-\mathrm{K} ; \overline{\mathrm{C}}_{\mathrm{PH}_{2}}$ is 8.06

cal/gmol-K; and $\bar{S}_{p_{H C l}}$ is $8.41 \mathrm{cal} / g$ mol-K. Thus, the theoretical flame temperature, $T_{f}$, is $1810 \mathrm{~K}$.

\subsubsection{Calculations for the Vaporizer}

The vaporizer is a stainless-steel container on a hot plate; it holds enough $\mathrm{TiCl}_{\mp}$ iu operate for $: 0 \mathrm{~h}$. In addition, it has a large vapor volume so that the vapor drawoff will not cause appreciable pressure fluctuations. The system operates at an equilibrium vapor pressure of 2 atm abs, to permit flow controls. The Antoine equation for $\mathrm{TiCl}_{4}$ is given as follows (10):

$$
\log P=7.64433-\frac{1947.6}{273.16+T}
$$

where $P$ is in $\mathrm{mm} \mathrm{Hg}$, and $t$ is in ${ }^{\circ} \mathrm{C}$. The vapor prezsure is $2 \mathrm{~atm}$ abs $(1520$ $\mathrm{mm} \mathrm{Hg)} \mathrm{at} 163.28{ }^{\circ} \mathrm{C}$.

The volumetric flow rate of the vapor at the conditions inside the vaporizer is calculated from the ideal gas law:

$$
\dot{v}=\frac{\dot{n} R T}{p}
$$

where $\dot{n}$ is $0.21 \mathrm{~mol} / \mathrm{h}, T$ is $436 \mathrm{~K}, P$ is $2 \mathrm{~atm}$ abs., and $R=82.1 \mathrm{~cm}^{3}$-atm/ mol-K. Therefore the vapor flow rate is $3759 \mathrm{~cm}^{3} / \mathrm{h}$ at $2 \mathrm{~atm}$ abs and $436 \mathrm{~K}$.

The volumetric depletion rate of the liquid phase is $22.5 \mathrm{~cm}^{3} / \mathrm{h}$; thus $225 \mathrm{~cm}^{3}$ of liquid must be charged to the vaporizer for a $10-\mathrm{h}$ run. A total vaporizer volume of ! liter provides adequate vapor space.

The hea: duty of the vaporizer at steady state consists of the energy to vaporize the liquid and that required to make up for heat losses to the atmosphere. The former is approximateiy $2.05 \mathrm{~W}$, while the latter is calculated to be $46.7 \mathrm{~W}$ for conservative conditions (see calculation file). Since the smallest available hot plate is rated at $840 \mathrm{~W}$, it was selected.

\subsubsection{Scrubber Dimensions}

The scrubber designed was based on a flooding correlation discussed in the Chemical Engineers' Handbook (15). Calculations are based on the following conservative assumptions:

1. All of the $\mathrm{BCl}_{3}$ and $\mathrm{TiCl}_{4}$ is converted to $\mathrm{TiB}_{2}$. In actuality we expect only $29 \%$ with the remaining $\mathrm{TiCl}_{4}+\mathrm{BCl}_{3}$ being absorbed in the scrubber. 
2. Two moles of $\mathrm{Cl}_{2}$ are burned per mole $\mathrm{TiCl}_{4}$ to provide the heat of reaction.

3. A three-times excess of $\mathrm{H}_{2}$ over tiat needed to convert the $\mathrm{TiCl}_{4}$ plus any hydrogen needed to burn the chlorine is used in the process.

4. The feed of $\mathrm{TiCl}_{4}$ is that needed to produce the desired amount of $\mathrm{TiB}_{2}$ using a conversion of $\mathrm{TiCl}_{4}$ equal to 0.29 .

Hith these assumptions the scrubber wiil be designed to handle the maximum gas flow rate.

The water flow rate was chosen so that if a maximum a ount of $\mathrm{HCl}$ were formed and all of it were absorbed in the water, the resulting solution would be $0.1 \mathrm{M} \mathrm{HCl}$. For these conditions the gas flow rates are given in Table 7.

Table 7. Reactor Feed and Product Flow Rates Based on Total Lonversion Assumption

\begin{tabular}{ccc}
\hline Gas & Feed (mol/h) & Product (mol $/ \mathrm{h})$ \\
${_{4}} }$ & 0.237 & - \\
$\mathrm{BCl}_{3}$ & 0.474 & - \\
$\mathrm{Cl}_{2}$ & 0.474 & - \\
$\mathrm{H}_{2}$ & 4.029 & 2.370 \\
$\mathrm{HCl}$ & - & 3.318 \\
\hline
\end{tabular}

The required water flow rate is calcuiated from:

$0.1 \mathrm{~mol} / 1$ iter $\mathrm{HCl}=\frac{3.318 \mathrm{moles} \mathrm{HCl} / \mathrm{h}}{\mathrm{L}}$

where $L$, the liquid flow rate, is $33.18 \mathrm{liter} / \mathrm{h}=0.0203 \mathrm{lb} / \mathrm{s}$. Since the gas flow rate is the highest at the bottom, the column will be sized based on flooding at that point.

The gas flow rate $G$ is given by the following expression:

$$
G=\dot{n}_{1}\left(m_{1}\right)+\dot{n}_{2}\left(m_{2}\right)
$$


where $\dot{n}_{1}\left(\mathrm{H}_{2}\right.$ flow rate) $=2.37 \mathrm{~mol} / \mathrm{h}$ and $\dot{n}_{2}(\mathrm{HCl}$ flow rate) $=3.318 \mathrm{~mol} / \mathrm{h}$. Equation (23) yields the following results:

$$
G=125.77 \mathrm{~g} / \mathrm{h} \text { and } \mathrm{m}_{\mathrm{avg}}=21.88 \mathrm{~g} / \mathrm{gmol}
$$

The density of the gas stream is calculated from the ideal gas law:

$$
\rho_{g}=\frac{(\mathrm{ww})_{\mathrm{avg}^{\mathrm{P}}}}{R T}=\frac{(21.85)(1)}{(0.7302)(536)}=0.3558 \mathrm{lb} / \mathrm{ft}^{3}
$$

The flooding velocity is obtained from Fig. 18-38 (15). The following abscissa is required:

$$
\frac{L}{G}\left(\frac{\rho_{g}}{\rho_{l}}\right)^{\frac{1}{2}}=\left(\frac{0.0203}{7.7 \times 10^{-5}}\right)\left(\frac{0.0558}{62.4}\right)^{\frac{1}{2}}=7.9
$$

Since the rings will be dumped rather than stacked in the column, the ordinate read from Fig. 18-38 (15) is:

$$
\frac{U_{\mathrm{T}}^{\mathrm{a}} \mathrm{p}}{\mathrm{g \varepsilon}^{3}}\left(\frac{\rho_{\mathrm{g}}}{\rho_{\ell}}\right)_{\mu}^{0.2}=0.0018
$$

where

$$
\begin{aligned}
U_{T} & =\text { superficial gas velocity, } \mathrm{ft} / \mathrm{s} \\
a_{p} & =\text { total area of packing, } \mathrm{ft}^{2} / \mathrm{ft}^{3} \text { bed } \\
\varepsilon & =\text { void fraction of dry packing } \\
g & =32.2 \mathrm{ft} / \mathrm{s}^{2} \\
{ }_{\mathrm{g}}, p_{\ell}= & \text { gas, liquid densities, } i \mathrm{i}, \mathrm{ft}^{3}=62.4 \text { and } 0.0558, \\
\mu & =\text { liquid viscosity, } \mathrm{cp}=0.89 \mathrm{cp} \text { for water at } 25^{\circ} \mathrm{C}
\end{aligned}
$$

The one-half inch Raschig rings which are used as packing have the following characteristics: the area of the packing $a_{0}$ is $112 \mathrm{ft}^{2} / \mathrm{ft}^{3}$ of bed, and the void fraction of the packing: is 0.64 . From these values one may calculate $U_{T}$, the superficial gas velocity, as $0.267 \mathrm{ft} / \mathrm{s}(8.14$ 
$\mathrm{cm} / \mathrm{s}$ ), above which gas velocity flooding may occur. The volumetric flow rate of the gas at the botton of the column is $38.66 \mathrm{~cm}^{3} / \mathrm{s}$.

The area of the column is then calculated by dividing the volumetric flow rate by the area and setting it equal to the linear flow rate. The minimum area is $4.25 \mathrm{~cm}^{2}$, yielding a diameter of $2.46 \mathrm{~cm}$. Thus, a colum of $10-\mathrm{cm}$ diameter is substantially removed from the flooding velocity. The column height, $45 \mathrm{~cm}$, was selected to ensure total removal of the HCl.

\subsubsection{Calculation of the Vacuum Pump Capacity}

The desired collection-trap pressure is approximately 1 torr. The gas flow rate into the scrubber, $V_{2}$, is $38.66 \mathrm{~cm} 3 / \mathrm{s}(2.281$ iter/min) at $1 \mathrm{~atm}$ pressure $\left(P_{1}\right)$ and $298 \mathrm{~K}$. At iower pressures, $P_{2}$, the volumetric flow rate changes so that the molar flow rate is constant.

$$
\dot{v}_{2}=i_{1}\left(\frac{p_{1}}{P_{2}}\right)=2.28\left(\frac{760}{1}\right)=1732 \text { liter } / \mathrm{min}
$$

If liquid-nitrogen cold traps are placed before the vacuum pump, only the $\mathrm{H}_{2}$ will be pumped out of the system. This would reduce the pumpingrate requirement to 1023 liter/min to maintain a pressure of 1 torr in the collectors. Sargent-Helch suggests that the pump capacity be double the actual requirement $(\mathbf{8})$. Thus a pump which wiil maintain a 1 -torr vacuum and a pumping capacity of $228001 \mathrm{iter} / \mathrm{m}$ atom torr is required.

\subsection{Equipment List and Cost}

The following is a list of the major pieces of equipment and services to be purchased. Also listed are the suggested vendor and current prices as well as the use of the equipment. This list is the basis for the overall cost estimate and is given in May 1981 dollars.

\section{Unit - Preheater-Reactor}

$\begin{array}{ll}\text { 1. I each } & \begin{array}{l}\text { Furnace (Lindberg) } \\ 1500^{\circ} \mathrm{C} \text { maximum temperature } \\ 4-\text { in- } 10 \text { tube } \\ 30-\text { in. heated zone } \\ \text { controller and transformer }(240 \mathrm{~V}) \\ \text { USE: reactor wall heater }\end{array} \\ \text { 2. } 1 \text { each } & \begin{array}{l}\text { Variac (Union Carbide Stores) } \\ 7.5 \mathrm{KVA}\end{array} \\ & 20 \text { amp } \\ & \text { USE: preheater temperature controller }\end{array}$


3. Alumina tubes (McDanel)

998 alumina $\left(99.8 \% \mathrm{Al}_{2} \mathrm{O}_{3}\right)$

gas tight

a) 1 each $3-3 / 8$ in. ID

$\$ 700.00$ each

$3-3 / 4$ in. length

55 in. length

open both ends

USE: outer housing and reactor vessel

b) 1 each $7 / 16$ in. $10^{2}$

$11 / 16$ in. 00

43.00 each

231 in. length

open both ends

USE : inner preheater tube

c) 1 each 1 in. $10^{2}$

55.00 each

11 in. 10

$21-11 / 16$ in. length

open both ends

USE: outer preheater tube

d) 1 each 1 in. ID

$3 / 8$ in. $0 D$

481 in. iength

closed one end

USE: reactor wall thermocouple well

e) 1 each $3 / 16$ in. ID

27.00 each

1 in. OD

$17-3 / 4$ in. length

closed one end

USE: preheater wall thermocouple well

f) 1 each 1-5/8 in. ID

$1-7 / 8$ in. 00

78.00 each

$7-7 / 8$ in. length

open both ends

USE: radiation shield

g) 1 each $2-1 / 8$ in. ID

$2-3 / 8$ in. 00

$7-7 / 8$ in. length

open both ends

USE : radiation shield

39.00 each

h) 1 each $2-3 / 4$ in. 10

67.00 each

101 in. length

open both ends

USE: radiation shield

49.00 each 
4. Alumina flats (McDanel)

998 alumina $\left(99.8 \% \mathrm{Al}_{2} \mathrm{O}_{3}\right)$
a) 2 each 3-3/4 in. long
$\$ 9.00$ each
$2-1 / 8$ in. wide
$1 / 8$ in. thick

USE: reactor outlet radiation shields
b) 2 each 3-3/4 in. long
3 in. wide
$1 / 8$ in. thick
USE: reactor outlet radiation shields
c) 3 each
2-3/16 in. diam, circular

$1 / 8$ in. thick

USE: preheater radiation shields

d) 13 each 2-3/4 in. diam, circular

9.00 each

$1 / 8$ in. thick

USE: preheater radiation shields

e) 1 each 3-3/8 in. diam, cylindrical

2 in. thick

USE: cone at the entrance of reactor

5. Miscellaneous parts

300.00

6. Construction Costs (Union Carbide craftsmen)

3 man/days

$1000.00(3)$

Total Reactor Preheater Cost

$\$ 9838.00$

\section{Unit - Feed System}

1. Mass flow meter (Matheson) ${ }^{3}$
a) 1 each Power supply and readout box
Handles up to 5 transducers
750.00 each
Model 8143
b) 4 each
Flow transducers
316 stainless stee 1
1 each capable of handiing
$1230 \mathrm{cc} / \mathrm{min} \mathrm{H}_{2}$
$78.5 \mathrm{cc} / \mathrm{min} \mathrm{TiCl}_{4}$
$157 \mathrm{cc} / \mathrm{min} \mathrm{BCl} 3$
$37.3 \mathrm{cc} / \mathrm{min} \mathrm{Cl} 2$
All flows are at $273 \mathrm{~K}, 1$ atm pressure
USE: flow measurement on all feed lines 
2. 4 each Valves (Nu Pro)

$\$ 212.30$ each

Bellows metering valves

Type "BNG"

stainless steel

$1 / 4$ in. Swagelok fittings

Cat NSS-4 BMG

USE: control thie feed flow rates

3. each Hot plate (Cole-Parmer)

73.00 each

840 w capacity

$700^{\circ} \mathrm{F}$ maximum temperature

Cat \$4659-00

USE: vaporizer heat source

4. 2 each Flash arrestors (Matheson)

Check valve and stops

flash back

$t$ in. $x \neq$ in. NPT

Model 6103

USE: $\mathrm{H}_{2}$ and $\mathrm{Cl}_{2}$ feed lines

Total Feed System Cost

3878.20

Unit - Collection/Disposal System

1. I each Vacuum pump (Sargent-Welch)

6132.00 each

Ul timate vacuum < l torr

Flow rate $2600 \mathrm{liter} / \mathrm{min}$ at 1 torr, $298 \mathrm{~K}$

Pump motor and drive

Model 1396

USE: to maintain the system pressure

2. Valves (Whitey)

a) 11 each Ball values

stainless steel

53.00 each

in. Swage lok fittings

Cat \#22-45S-8

USE: shut off and isolation of collection traps

b) 2 each Vee stem valves

100.50 each

stainless steel

in. Swagelok fittings

Cat "SS-7VS-8

USE: regulate reactor and collector pressure

3. 3 each Pressure gauges (Matheson)

175.00 each

$0-760$ torr abs

316 stainless steel

$0.25 \%$ full-scale accuracy

Model 63-5601 
4. 1 each Mass flow transducer

$\$ 525.00$ each

316 stainless steel

Capabie of handling the product flow, instly $\mathrm{H}_{2}$

Approximately 1200 scfin with a pressure of $\sim 200$ torr and temperature of $200^{\circ} \mathrm{C}$

To be used with the readout box for the feeds

Total Collection/Disposal System Cost

$\$ 8499.39$

\section{NOTES FOR EQUIPMENT LIST:}

1. This furnace must be special-ordered. The specifications must be sent to Lindberg and firm price is requested. To bracket the cost of this furnace, two units were priced, one larger than required and one smaller.

a) Smaller Unit

4-in. ID

24-in. heated length

Single-zone furnace

Controller and transformer (240 V) Total
$\$ 3685$

$\underline{970}$

$\$ 4655$

$\$ 5675$

4-in. ID

36-in. heated length

Three-zone furnace

Controller and transformer (240 V)

Total

A $\$ 7000$ price estimate was selected.

2. These two tubes must be ground to a wall thickness of 25 mils. Since the inside diameter is corract, grinding of the exterior will be required to arrive at the desired irall thickness. McDanel is capatile of performing this work, but it $i$; not included in the cost. All other tubes may be used as received.

3. The mass flow meter could be converted to a mass flow controller. This is accomplished by substituting the power supply and controller box Model 8249 (at $\$ 1500$ each) for Model 8143 . Four control valves must be added at $\$ 250$ each.

4. The flow rate of the vacuum pump is very pressure-dependent. In our case it is given by $F=1732 / P$, where $F$ is the flow rate in liter/min at a given pressure $P$ torr. If an ultimate vacuum of only 5 torr is to be obtained in any part of the system rather than the 1 torr which was specified, then the pump capacity must be $F=1732 / 5$ or 346.4 liter/min. The pump which is specified should be 1.5 to 2 times the 
capacity actually required (8). Thus a pump with a $692.8 \mathrm{liter} / \mathrm{min}$ puming rate could be specified if a Storr vacuum is used rather than the 1-torr pressure specified in the original calculations. The smaller pump for the Stcrr pressure system could represent a substantial cost reduction.

\subsection{List of Vendors}

The following is a list of vendors whose product information was used in calculating the costs. In some cases, contact was made to ascertain technical information on the product in question.

Cole-Parmer

7425 N. Oak Park Ave.

Chicago, IL 60648

phone: (800) 323-4340

Product: hot plate

Lindberg, Inc.

2450 H. Hubbard St.

Chicago, IL 60612

phone: (312)942-2600

Product: furnace

Matheson

1805 Southlaind Dr.

Gonzales, LA 70737

phone: (504)644-5303

Products: mass flow meters, pressure gauges, gases

McDanel Refractory Co.

510 Ninth Ave.

Beaver Falls, PA 15010

phone: (412)843-8300

Products: alumina parts and tubes

National Element

42201 iver Ave.

Troy, MI 48084

phone: (313)362-0950

Products: molybdenum heating elements

Omega Engineering

One Omega Drive

Box 4047

Stamford, CT 06907

phone: (203)359-1660

Products: thermocouples and accessories 
Ridge Valve and Fitting Co.

P.0. Box 10086

Knoxville, TN 37919

phone: (615)588-2414

from Oak Ridge: 483-0211

Products: Mupro and Whitey valves and Swagelok fittings

Sürgent-Helch

$730 \mathrm{C}$ N. Linden Ave.

Skokie, IL 60076

phon ?: (312)677-0600

Product: vacuun pumps

\subsection{Nomenclature}

a total area per unit volume, $f t^{3} / f t^{2}$

A area, $\mathrm{cm}^{2}$

$C_{p}$ heat capacity, cal/gmol-K, Bt.j/lb- ${ }^{\circ} \mathrm{F}$

d diameter, cm

D diameter, cm

f molar feed rate, mol/h

F total volumetric flow rat- $. .3 / \mathrm{min}$

9 acceleration due to gravity, $? \mathrm{rr} / \mathrm{s}^{2}$

$G$ mass gas flow rate, $g / h$ or $1 b / s$

h convective heat transfe $i^{*}$ coefficient, cal/s-cm ${ }^{2}-K$ or $B t u / h-\mathrm{ft}^{2}-{ }^{\circ} \mathrm{F}$

H entralpy, kcal/mole, cai/mole

$k$ thermal conductivity, Btu/h-ft- ${ }^{\circ} \mathrm{F}$

$k$ equilibrium constant, atm ${ }^{2}$

$L$ mass liquid flow rate, $1 \mathrm{~b} / \mathrm{s}$; length, $\mathrm{cm}$ or $\mathrm{ft}$

mw molecular weight, $g / g m o l e$ or $1 b / 1 b_{m}$

$n$ number of moles, mole

n molar flow rate, moles/h

$N$ dimensionless quantity 
P pressure, atm or $\mathrm{mm} \mathrm{Hg}$

Q heat duty, kcal/mole, or $H$, or cal/s, or $\mathrm{kcal} / \mathrm{h}-\mathrm{min}$, or $\mathrm{kcal} / \mathrm{h}-\mathrm{in}$.

$R$ gas law constant, $\mathrm{cm}^{3}$-atm/mol-K or liter-atm/mol-K or $\mathrm{ft}^{3}-\mathrm{atm} / \mathrm{lt} \mathrm{m}^{-R^{2}}$

$R$ radius, $\mathrm{cm}$

$t$ temperature, ${ }^{\circ} \mathrm{F}$

$T$ temperature, $\mathrm{K} J \mathrm{Jr}^{\circ} \mathrm{C}$

U Superficial mass velocity, $\mathrm{ft} / \mathrm{s}$ or $\mathrm{cm} / \mathrm{s}$

i volumetric flow rate, $\mathrm{cm}^{3} / \mathrm{min}$ or $\mathrm{cm}^{3} / \mathrm{h}$, or 1 iter $/ \mathrm{min}$, or $\mathrm{cm}^{3} / \mathrm{sec}$

v reactor volume, $\mathrm{cm}^{3}$

$x \quad$ mole fraction, dimensionless

y equilibrium conversion, moles

\section{Greek Symbols}

B coefficient of thermal expansion, ${ }^{\circ} \mathrm{F}^{-1}$

$\varepsilon \quad$ void fraction, dimensionless; emissivity, dimensionless

$\tau$ residence time, $s$

$\rho$ density, $\mathrm{g} / \mathrm{cm}^{3}$ or $1 \mathrm{~b} / \mathrm{ft}^{3}$

o Stefan-Boltzmann con;tant, $\mathrm{cal} / \mathrm{cm}^{2}-s-K^{4}$

$\mu \quad$ viscosity, Ib/ft-h or cp

\section{Subscripts}

$1,2,3 \ldots$ components or states

¿ 18 at $298 \mathrm{~K}$

B boron trichloride

f flame, theoretical

9 gas

Gr Grashoff number

$\mathrm{H}_{2}$ hydrogen

i species $i$ 
e liquid

Nu Nusselt number

- feed conditions

p pressure

Pr. Prandtl number

ref reference state

$t$ at flooding

$T$ tube

Ti titanium tetrachloride

tot total

vap vaporization

w wall

Superscript

- standard state

\subsection{Literature References}

1. Besmann, T.M., and K.E. Spear, "Analysis of the Chemical Vapor Deposition of Titanium Diboride," Parts I and II, J. Electrochem. Soc., 124, 786 (1977).

2. Besmann, T.M., and K.E. Spear, "Morphology of Chemical Vapor Deposited TiB2," J. Crystal Growth, 31, 60 (1975).

3. Earley, E.L., personal communication, ORNL, May 1981.

4. Federer, J.I., W.C. Robinson, Jr., and F.H. Patterson, "Conversion of $\mathrm{UF}_{6}$ to $\mathrm{UO}_{2}$ in a Flame Reactor," Nucl. Applications, 6, 298 (1969).

5. Formenti, M., F. Juillet, P. Meriaudeau, S.J. Teichner, and P. Vergnon, "Preparation in a Hydrogen-0xygen Flame of Ultrafine Metal Oxide Particles," J. Coll. Sur. Sci., 39(1), 79 (1972).

6. George, A.P., R.D. Murley, and E.R. Place, "Formation of $\mathrm{TiO}_{2}$ Aerosol from the Combustion Supported Reaction of $\mathrm{TiCl}_{4}$ and $\mathrm{O}_{2}$, "Faraday Soc. Symp., No. 7 (1973). 
7. Grjotheim, K., ¿. Krohn, M. Mal inovsky, K. Mathiakovsky, and J. Than stad, 'Aluminum Electrolysis," Aluminum Verlag $\mathrm{GmgH}$, Dusseldorf, p. 333 (1977).

8. Hansen, D., Sargent-Helch Scientific Co., Skokie, IL., May, 1981.

9. Heestand, R.L., and C.F. Leitten, "Thermochemical Reduction of Uranium Hexafluoride for the Direct Fabrication of Uranium Dioxide Ceramic Fue 1s," Nuclear Applications, I (6), 584 (1965).

10. Kirk-0thmer, Encyclopedia of Chemical Technology, 2nd ed., Vol. 20, Wiley, New York, 1963. (1970).

11. Matheson Gas Products, Matheson Gas Data Book, Milwaukee, Wis.

12. McDanel Refractory Co., personal comunication, Beaver Falls, Pa., May 1981.

13. Merriman, J.R., S.H. Smiley, and H.L. Kaufman, :Preparation of Unusual Refractory Powders by Flame Processes," Proc. Conf. Chemical Vapor Deposition of Refractory Metals, Alloys, and Compounds, Gatlinburg, TN, Sept. 12-14-1967, pp. 229-242, American Nuclear Society, Hinsdale, IL (1967).

14. National Element, personal communication, Troy, MI, May 1981.

15. Perry. R.H., and C.H. Chilton, Chemical Engineers' Handbook, 5th ed., Sect. 18, McGraw-Hill, New York (1969).

16. Stull, D.R., and H. Prophet, JANAF Thermochemical Tables, 2nd ed., U.S. Govt. Printing Office, Washington, D.C. (1971).

17. Tek, M.R., and J.0. Wilkes, "Notes and Problems in Fluid Flow and Heat Transfer," Univ. of Michigan, Ann Arbor (1974). 